Boletín de la Sociedad Geológica Mexicana

VOLUMEN 62, NÚM. 3, 2010, P. 325-343

\title{
Registro sedimentario de los últimos ca. 17000 años del lago de Zirahuén, Michoacán, México
}

\author{
Gabriel Vázquez ${ }^{1, *}$, Beatriz Ortega ${ }^{2}$, Sarah J. Davies³, Benjamin J. Aston ${ }^{3}$ \\ ${ }^{1}$ Posgrado en Ciencias de la Tierra, Universidad Nacional Autónoma de México. México, D.F. 04510. \\ ${ }^{2}$ Instituto de Geofísica, Universidad Nacional Autónoma de México. México, D.F. 04510. \\ ${ }^{3}$ Institute of Geography and Earth Science, Aberystwyth University. Aberystwyth, Gales, Reino Unido, SY23 3DB. \\ *gvazquez@geofisica.unam.mx
}

\section{Resumen}

El lago Zirahuén $\left(101^{\circ} 44^{\prime} \mathrm{W}, 19^{\circ} 26^{\prime} \mathrm{N}\right)$, ubicado en un campo volcánico activo, en la frontera moderna de la influencia de los sistemas atmosféricos zona de convergencia intertropical y zona subtropical de alta presión, con una historia de ocupación humana de varios miles de años, ofrece la oportunidad de investigar las variaciones climáticas, la historia de la vegetación, el impacto del volcanismo y la actividad humana en la región. En este trabajo se presenta un modelo preliminar de la evolución del lago de Zirahuén de los últimos 17000 años cal AP, basado en el análisis de las variaciones verticales y laterales del depósito sedimentario, a partir de dos núcleos de sedimentos colectados en el centro y norte del lago (5.40 y $6.61 \mathrm{~m}$ de longitud). Las facies sedimentarias han sido agrupadas en cuatro asociaciones que describen la evolución sedimentaria de la sección centro-norte del lago. Los registros de susceptibilidad magnética apoyan la correlación entre las secuencias. El control cronológico es proporcionado por 20 fechamientos de ${ }^{14} \mathrm{C}$ y el reconocimiento de dos tefras históricas de los volcanes Jorullo y Paricutín. De acuerdo a los modelos de edad, los sedimentos en la secuencia norte abarcan 17000 años cal AP, en tanto los de la secuencia central 11540 años. Las facies consisten de oozes diatomáceos (masivos o laminados), facies clásticas y facies volcaniclásticas. En la secuencia norte evidencias estratigráficas sustentadas en la cronología de 20 fechas de ${ }^{14} \mathrm{C}$ indican un hiato en la sedimentación de aproximadamente $1 \mathrm{~m}$, equivalente a 5000 años, por lo que las secuencias se traslapan en edades posteriores a 7200 años cal AP. La evolución del lago Zirahuén inferida a partir de las variaciones de los componentes sedimentarios analizados en los últimos 17000 años se resume en cuatro etapas. 1) 17000 a 14000 años cal AP: bajos niveles lacustres y dominancia de sedimentación clástica de grano fino. 2) 14000 a 8180 años cal AP: aumento en el nivel lacustre y expansión litoral bajo condiciones relativamente estables. Entre 8180 y 7200 años cal AP se produce un evento erosivo que origina el hiato en la secuencia norte. 3) 8180 a 3900 años cal AP: ascenso del nivel lacustre. 4) Para los últimos 3900 años se registra un intenso aporte de terrígenos, derivado posiblemente del efecto erosivo de esporádicas y fuertes precipitaciones sobre un terreno con una pobre cubierta vegetal. Para este periodo es difícil separar las señales climáticas y de impacto humano, ya que la agricultura y otras actividades humanas han sido documentadas en la región. Se reconoce un periodo de baja erosión entre hace 1400 y 880 años, que sugiere la extensión de las condiciones secas inferidas en otros sitios de Mesoamérica al final del periodo arqueológico del Clásico.

Palabras clave: Pleistoceno tardío, Holoceno, paleolimnología, sedimentos lacustres, tefras, centro de México.

\begin{abstract}
Lake Zirahuen $\left(101^{\circ} 44^{\prime} \mathrm{W}, 19^{\circ} 26^{\prime} \mathrm{N}\right)$, located in a volcanically active region at the boundary of the two major modern climatic systems (the intertropical convergence zone and the subtropical high pressure zone) and in a region with a history of human occupation of several thousand years, provides the opportunity to investigate climatic variations, the history of vegetation and the volcanic and anthropogenic impact in central Mexico. In this paper, we present a preliminary model of lacustrine evolution of Zirahuen Lake for the last 17000 cal yr BP, based on the analysis of vertical and lateral variations of this sedimentary deposit, using two sediment cores
\end{abstract}


collected in the center and northern part of the lake (5.40 and $6.61 \mathrm{~m}$ depth). The described sedimentary facies have been grouped into four facies associations, which describe the sedimentary evolution of the central-north part of the lake. Core log correlation is supported by matching the magnetic susceptibility peaks. The chronological framework is provided by twenty ${ }^{14} \mathrm{C}$ dates and the recognition of two historical tephras from Jorullo and Paricutin volcanoes. According to the age models, the northern sedimentary sequence spans ca. 17000 cal yr BP, while the central one covers 11540 cal yr BP. The facies are composed of diatomaceous ooze (massive or laminated), clastic facies and volcaniclastic facies. In the northern sequence, stratigraphical and chronological evidence point to a sedimentary hiatus of nearly $1 \mathrm{~m}$, equivalent to $5000 \mathrm{yr}$. In consequence, the two sedimentary sequences are only correlated for the last 7200 cal yr BP. The evolution of Zirahuen Lake for the last $17000 \mathrm{yr}$ as inferred from the variations in the sedimentary components is summarized in four stages: 1) 17000-14000 cal yr BP-low lake levels and dominance of fine-grained clastic sedimentation; 2) 14000-8180 cal yr BP-increase in lake level and littoral expansion under relatively stable conditions, and between 8180 and 7200 cal yr BP, an erosive event that gave origin to the hiatus in the northern sedimentary sequence; 3) 8180-3900 cal yr BP-lake level increases; and 4) the last 3900 yr are characterized by intense erosion and clastic sedimentation. Sporadic heavy precipitation over land with scarce vegetation probably induced the high erosion. For this period, it is difficult to separate the climatic and anthropogenic signals, as agriculture and other human land uses have been documented for the region. A low erosion period is recognized between 1400 and 800 yr ago, suggesting the extension of dry conditions inferred from other sites in Mesoamerica at the end of the archaeological Classic period.

Keywords: Late Pleistocene, Holocene, paleolimnology, lacustrine sediments, tephras, central Mexico.

\section{Introducción}

La historia de los cambios ambientales y climáticos de una región puede conservarse en varios archivos geológicos, tanto marinos como continentales. La continuidad y el grado de preservación de estos archivos dependen de la naturaleza de los ambientes de depósito y de los procesos posteriores a la acumulación de los sedimentos. Debido a que en los lagos ocurre una rápida acumulación, los sedimentos lacustres responden prontamente a los cambios ambientales, por lo que pueden reflejar la historia completa del entorno en escalas resolutivas que alcanzan variaciones interanuales. En ocasiones, los sedimentos lacustres están caracterizados por horizontes laminados. Las laminaciones pueden corresponder a cambios en el aporte clástico durante la sedimentación, variaciones en la producción de organismos planctónicos y bentónicos, o por procesos fisicoquímicos (Zolitschka et al., 2000). La preservación de la laminación en los sedimentos lacustres puede estar controlada por la profundidad y la morfología del lago, en ausencia de bioturbación -condición común en ambientes anaeróbicos, y donde las corrientes cercanas al piso del lago están ausentes (Clausing y Boy, 2000). El desarrollo de láminas está condicionado por factores ambientales, en particular por la precipitación y por la insolación, y puede ser episódica o periódica, estacional a multianual.

Los lagos del centro de México han proporcionado información sobre la variabilidad climática de los últimos miles de años, derivada de indicadores biológicos, geoquímicos y mineralógicos (p.e. Bradbury, 1989; Metcalfe et al., 1991; Lozano et al., 1993). Sin embargo, con frecuencia las secuencias sedimentarias se encuentran alteradas o incompletas debido a que se trata de una región tectónica y volcánicamente activa, con una historia de ocupación humana de varios miles de años (p.e. Metcalfe,
1995; Caballero y Ortega, 1998; Lozano et al., 2005). Algunos registros lacustres provienen de lagos someros $(<$ $5 \mathrm{~m}$ de profundidad), en los cuales, durante los episodios de bajos niveles lacustres, los procesos erosivos originan hiatos en los sedimentos con intervalos temporales desconocidos (p.e. Lozano et al., 1998; Caballero et al., 1999).

En el centro-occidente de México las secuencias sedimentarias de las cuencas de Zacapu, Pátzcuaro y Cuitzeo han proporcionado escenarios fragmentados de condiciones climáticas y ambientales pasadas (Metcalfe, 1995; Bradbury, 2000; Ortega et al., 2002; Metcalfe et al., 2007; Israde et al., 2002). Algunos periodos críticos que permanecen poco conocidos son el fin del último glacial (entre 20000 y 11000 años antes del presente), el Holoceno medio (entre hace 8000 y 6000 años), y en tiempos más recientes, cuando las actividades humanas coexistieron con variaciones climáticas y las señales derivadas de ambos factores se confunden. En particular, Pátzcuaro ha sido extensamente estudiado con fines geológicos (p.e. Garduño et al., 2004) y arqueológicos (p.e. O'Hara et al., 1993; Fisher et al., 2003), además de los paleolimnológicos. De estos estudios, se derivan controversias tales como las relacionadas a las características climáticas durante el último máximo glacial (ocurrido hace $c a .20000$ años), o el grado y la antigüedad del impacto humano en Pátzcuaro. En este escenario, los estudios en secuencias prístinas o poco alteradas podrán resolver estas interpretaciones contradictorias.

El lago de Zirahuén ( $101^{\circ} 44^{\prime} \mathrm{W}, 19^{\circ} 26^{\prime} \mathrm{N}, 2075$ m snm) es uno de los lagos más profundos y de mayor altitud en la parte centro-occidental de México. Ha sido seleccionado como una localidad clave para estudiar las variaciones climáticas del Pleistoceno tardío y Holoceno debido a que se encuentra en la frontera de la influencia de los sistemas atmosféricos Zona de Convergencia Intertropical (ZCIT) y Zona Subtropical de Alta Presión (ZSAP), cuyas 
variaciones han ejercido un fuerte control en la precipitación de la región. También, el registro lacustre de Zirahuén es importante para investigar la historia de la vegetación, los cambios en la química del agua y en los niveles lacustres, la variabilidad en el suministro de sedimentos, el impacto de la actividad humana y de la actividad volcánica en el entorno del mismo.

Para desarrollar estos estudios, se extrajeron núcleos de sedimentos en la zona somera de la parte norte del lago y en la parte central profunda del mismo. Estos últimos fueron parte de un proyecto conjunto de investigación de las universidades de Aberystwyth (Gales), Nottingham (Inglaterra), Minnesota (EE.UU.), Michoacana de San Nicolás de Hidalgo (México) y la UNAM (México). El análisis sedimentológico y la correlación estratigráfica de estas secuencias permitieron reconstruir la arquitectura de la parte norte del lago, así como documentar el registro de la actividad volcánica. En este trabajo se presenta un modelo preliminar de la evolución del lago de Zirahuén, referido a una cronología basada en fechamientos de ${ }^{14} \mathrm{C}$, y basado en el análisis de las variaciones laterales y verticales de la sucesión lacustre, de las tasas de sedimentación, y de las características de las laminaciones.

\section{Localización, clima y características limnológicas}

El lago de Zirahuén (101 $44^{\prime} \mathrm{W}, 19^{\circ} 26^{\prime} \mathrm{N}, 2075$ m snm) se localiza en el campo volcánico MichoacánGuanajuato (CVMG) (Hasenaka y Carmichael, 1985), en la parte central de México (Figura 1). Está rodeado por depósitos volcaniclásticos basáltico-andesíticos de edad neógena, cubiertos por suelos y paleosuelos. Se encuentra en una cuenca endorreica limitada al norte por la cuenca del río Lerma y al sur por la del Balsas. La intensa actividad volcánica y tectónica en la región ha influido notablemente en el desarrollo del lago y en la formación de diversas estructuras geológicas como fallas y fracturas. La divisoria de aguas de esta cuenca en la porción norte coincide parcialmente con fracturas orientadas E-W, sobre las que se han construido varios edificios volcánicos, que también forman parte del borde sur de la cuenca del lago de Pátzcuaro (Figura 1). Es generalmente aceptado que Zirahuén se formó por el emplazamiento de los flujos de lava al occidente de la cuenca, en conjunto denominados como volcán La Magueyera, que cerraron el cauce del río La Palma (Bernal-Brooks y MacCrimmon, 2000a). Aunque no se dispone de fechamientos radiométricos absolutos de los depósitos volcánicos que rodean al lago y por lo tanto no se conoce la edad del inicio de la sedimentación lacustre en Zirahuén, los rasgos geomorfológicos y un fechamiento por termoluminiscencia sugieren que los flujos más jóvenes de La Magueyera tienen una edad entre 13000 y 6000 años calendario (Antes del Presente, AP) (Ortega et al., sometido).

Zirahuén es el lago más profundo de la región lacustre de Michoacán. Actualmente tiene una profundidad máxima de $c a .40 \mathrm{~m}$, presenta una forma pentagonal con $9.7 \mathrm{~km}^{2}$ de área. Es un lago monomíctico, que estratifica entre abril y octubre, cuando la termoclina se encuentra a ca. $15 \mathrm{~m}$

a)

b)

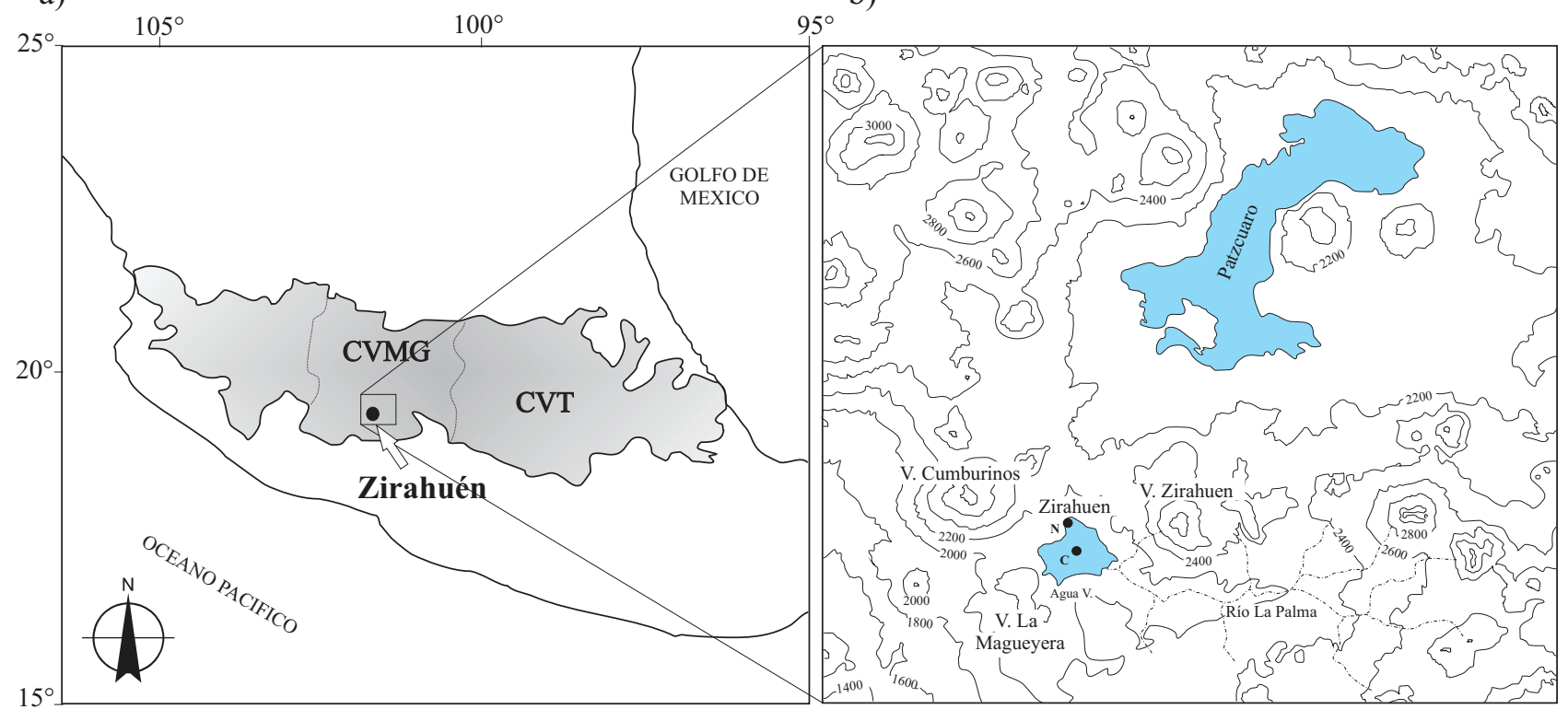

Figura 1. Mapa topográfico de localización del lago Zirahuén. a) Ubicación del Campo Volcánico Michoacán-Guanajuato (CVMG) dentro del Cinturón Volcánico Transmexicano (CVT). b) Localización de los lagos Zirahuén y Pátzcuaro, así como de los sitios mencionados en el texto: al SW del lago Zirahuén el volcán La Magueyera, al NW el volcán Cumburinos, al NE el volcán Zirahuén, la bahía sur del lago es Agua Verde y al E el río La Palma. Dentro del lago Zirahuén los puntos negros corresponden a la ubicación del sondeo central (C) y norte $(\mathrm{N})$. 
de profundidad. En el epilimnion, la temperatura oscila de 18.5 a $22.5{ }^{\circ} \mathrm{C}$ y la cantidad de oxígeno disuelto (OD) varía de 4.1 a $7.5 \mathrm{mg} / 1$. En el hipolimnion, estos valores se presentan en el rango de $16.5-19.0^{\circ} \mathrm{C}$ y OD $2.5-0 \mathrm{mg} / 1$ (Bernal-Brooks y MacCrimmon, 2000b). El nivel lacustre ha disminuido gradualmente desde los años 1940's. A partir del análisis de mapas topográficos se ha inferido una reducción de 6.6 m entre 1942 y 1995; por otro lado, a partir de fotografías aéreas entre 1974 y 1995 se ha documentado una disminución de $4.7 \mathrm{~m}$ y un desplazamiento del borde norte del lago de $108 \mathrm{~m}$ hacia el interior del mismo, así como también en su región SW (Agua Verde) y al SE en la desembocadura del río La Palma (Bernal-Brooks y MacCrimmon, 2000a). La ausencia de líneas de costa elevadas en la margen del lago sugiere que no han existido niveles lacustres por arriba de los documentados en el siglo pasado.

El clima en Zirahuén es templado subhúmedo con lluvias en verano $\left(\mathrm{Cw}_{2}\right)$ (García, 1990). Entre 1971 y 1992, la precipitación media anual fue de $1234 \mathrm{~mm}$ y la temperatura media anual fue de $16.1^{\circ} \mathrm{C}$ (Bernal-Brooks y MacCrimmon, 2000a). La precipitación en el verano (junio a septiembre) es aproximadamente el $80 \%$ del total anual. La temperatura varía de $32{ }^{\circ} \mathrm{C}$ (mayo) a $0{ }^{\circ} \mathrm{C}$ (enero). En la actualidad, la vegetación arbórea en la cuenca está compuesta de parches de bosques de pino y encino; alrededor del lago la vegetación de macrofitas está compuesta de Scirpus americanus, Typha latifolia y Cyperus niger. La deforestación para prácticas de agricultura y construcción de vivienda es evidente en toda la cuenca, lo que provoca una intensa erosión por las fuertes precipitaciones, especialmente durante las tormentas que son frecuentes entre el fin del verano y el otoño, durante las cuales el flujo superficial colorea de rojo el borde del lago.

\section{Material analizado y metodología}

En la primavera de 2003 se colectó en la zona norte del lago un núcleo de $6.61 \mathrm{~m}$ de longitud (ZIR03-I), bajo un tirante de agua de $c a .12 \mathrm{~m}$, con un sistema de perforación Usinger (Mingram et al., 2007) (Fig. 1). En lo subsecuente, se hará referencia a este núcleo como la secuencia norte $(\mathrm{N})$. En octubre de 2003 se obtuvieron tres sondeos entre 0.95 y $5.8 \mathrm{~m}$ de longitud de la parte central profunda del lago (MOLE ZIR03-1M, -2K y -3K), bajo un tirante de agua de $c a .40 \mathrm{~m}$, con un sistema de perforación Kullemberg modificado, de los que se obtuvo una secuencia maestra de $5.40 \mathrm{~m}$ de longitud. Los detalles de la correlación entre estos sondeos centrales y el establecimiento de la secuencia maestra representativa de este sitio fueron descritos en Israde et al. (en preparación). En adelante, se hará referencia a esta secuencia maestra como la central (C).

Los núcleos se abrieron longitudinalmente y se describió la estratigrafía de los sedimentos de ambos sitios, considerando la textura, color, composición, contenido fósil y estructuras sedimentarias, de acuerdo al protocolo establecido por Schnurrenberger et al. (2003). Se prepararon alrededor de 150 frotis de sedimentos de ambas secuencias para determinar la composición y estimar de manera semicuantitativa el contenido de los componentes clásticos, biogénicos y autígenos en microscopios estereográfico y petrográfico, lo que a su vez fue utilizado como base para definir las facies sedimentarias. De manera continua se tomaron muestras en cubos de acrílico de $2 \mathrm{~cm}$ de sección, donde fue medida la susceptibilidad magnética en un sistema Bartington en una frecuencia de $470 \mathrm{~Hz}$, expresada en unidades de masa específica $(\chi)$. En la secuencia norte fueron colectadas 313 muestras, en tanto que en la sección central 251 muestras. Adicionalmente fueron colectadas muestras en ambas secuencias aproximadamente cada 5 $\mathrm{cm}$ para análisis geoquímicos, mineralógicos y biológicos, cuyos resultados serán presentados en otras publicaciones. Para la identificación de las arcillas, se realizaron análisis de difracción de rayos X, en un difractómetro Phillips 1130/96 en ocho muestras de las secciones central y norte.

Las escalas de tiempo para cada secuencia fueron construidas a partir de fechamientos de ${ }^{14} \mathrm{C}$ AMS (acceleration mass spectrometry), diez en sedimento total en la secuencia $\mathrm{N}$ y en la secuencia maestra de la parte central del lago, cinco en sedimento total y cinco en extractos de polen. La relativa ventaja de utilizar extractos de polen para el fechamiento consiste en que, debido a que las rocas que circundan al lago son únicamente volcánicas, esta fracción representa de manera más fiel el material biológico contemporáneo al depósito, libre de efectos contaminantes tales como la inclusión de polen derivado de rocas pre-existentes, la incorporación de carbono de origen volcánico o por aguas subterráneas y la mezcla de material orgánico más antiguo.

\section{Resultados}

La litoestratigrafía de las secuencias norte y central y los modelos de edad correspondientes se presentan en las figuras 2 y 3 . Las facies descritas en las secuencias verticales representan la sucesión de diferentes ambientes a través del tiempo. Las facies que se infiere están genéticamente relacionadas, han sido agrupadas y sus asociaciones verticales y horizontales, sustentadas en las escalas de tiempo; la correlación estratigráfica entre ambas secuencias, puede interpretarse como una secuencia de eventos que describe la evolución sedimentaria de la sección centronorte del lago de Zirahuén.

\subsection{Cronología}

Los modelos de edad para cada sitio fueron definidos de acuerdo a las edades de radiocarbono obtenidas, seleccionadas y convertidas a años calendario por medio del programa Calib 5.0 (Stuiver y Reimer, 1993; Stuiver et al., 2005), utilizando el conjunto de datos de la curva de 


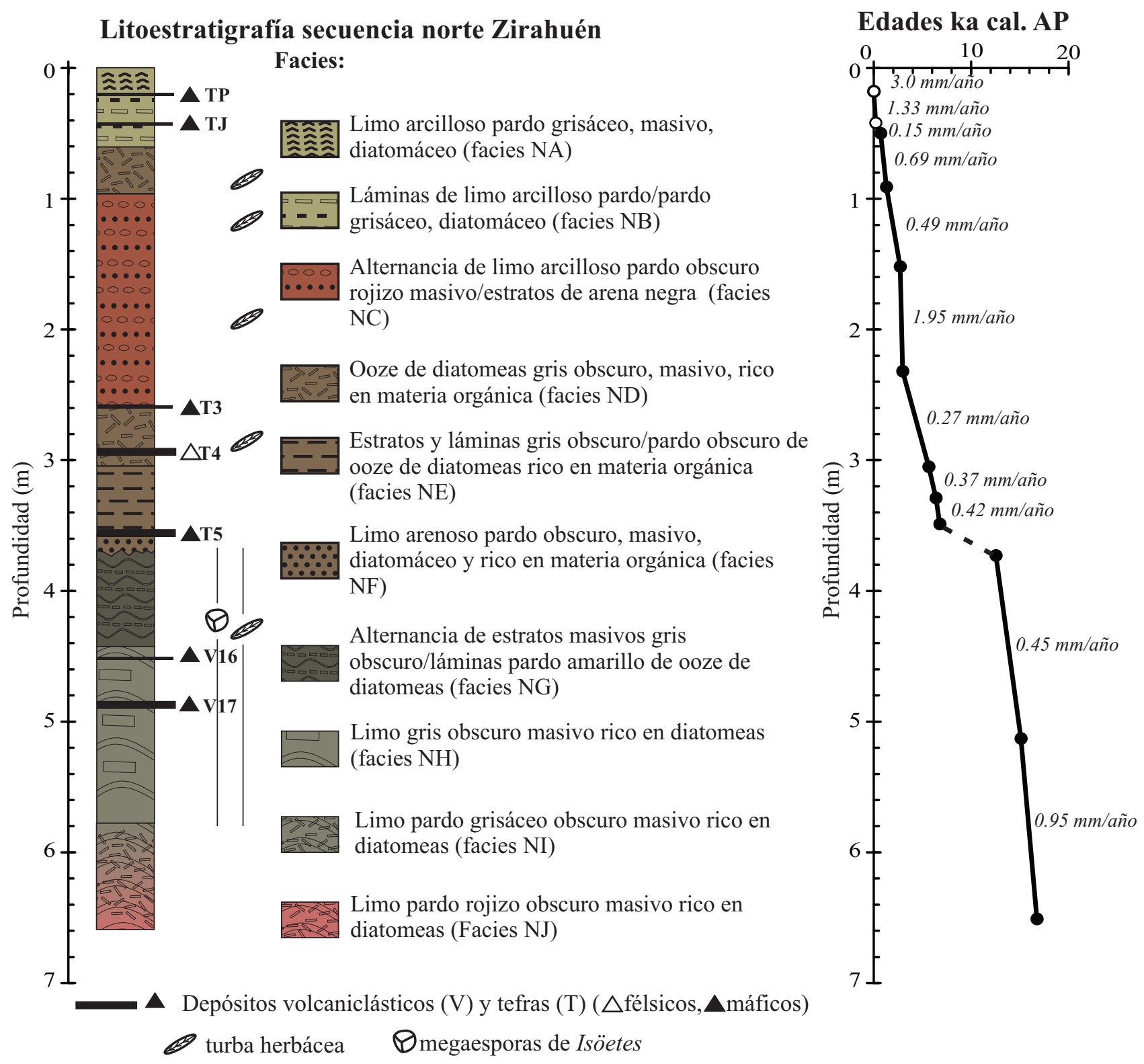

Figura 2. Litoestratigrafía y modelo de edad de la secuencia norte. La curva del modelo de edad fue construida con los valores medios del intervalo de probabilidad de $2 \sigma$ de las edades calibradas, e incluye las tasas de sedimentación calculadas entre cada intervalo fechado, considerando la edad de la cima del depósito como el año de la colecta (2003).

calibración IntCal04 (Reimer et al., 2004) (Tabla 1; figuras 2 y 3). El punto medio del intervalo de probabilidad de $2 \sigma$ $(95.4 \%)$ de las edades calendario así como la interpolación lineal entre edades adyacentes fueron utilizados para construir el modelo de edad-profundidad y para calcular la tasa de sedimentación entre los intervalos fechados, considerando la cima de las secuencias como el año de la colecta de sedimentos (2003). Adicionalmente, la existencia de dos tefras históricas de edad conocida, identificadas previamente en sondeos cortos colectados en diversas localidades del lago de Zirahuén (Davies et al., 2004; Newton et al., 2005), provee un control cronológico adicional. En los sondeos cortos de Davies y colaboradores, la tefra del volcán Jorullo (emitida entre los años 1759 y 1764) fue evidente solo en imágenes de rayos $X$ como bandas minerogénicas localizadas entre 0.43 y $0.28 \mathrm{~m}$ de profundidad (núcleos AV/98 y ZD/98). Esta tefra puede corresponder a los volcaniclastos diseminados entre 0.42 y $0.45 \mathrm{~m}$ de los sondeos presentados en este trabajo. La tefra del Paricutín (1943 - 1945), encontrada entre 0.08 y 0.03 $\mathrm{m}$ de profundidad de los núcleos cortos, corresponde a la tefra encontrada entre $0.18-0.12 \mathrm{~m}$ de profundidad en los sondeos norte y central, respectivamente. Los sedimentos más recientes fueron anteriormente fechados por ${ }^{210} \mathrm{~Pb}$ 
Litoestratigrafía secuencia central Zirahuén

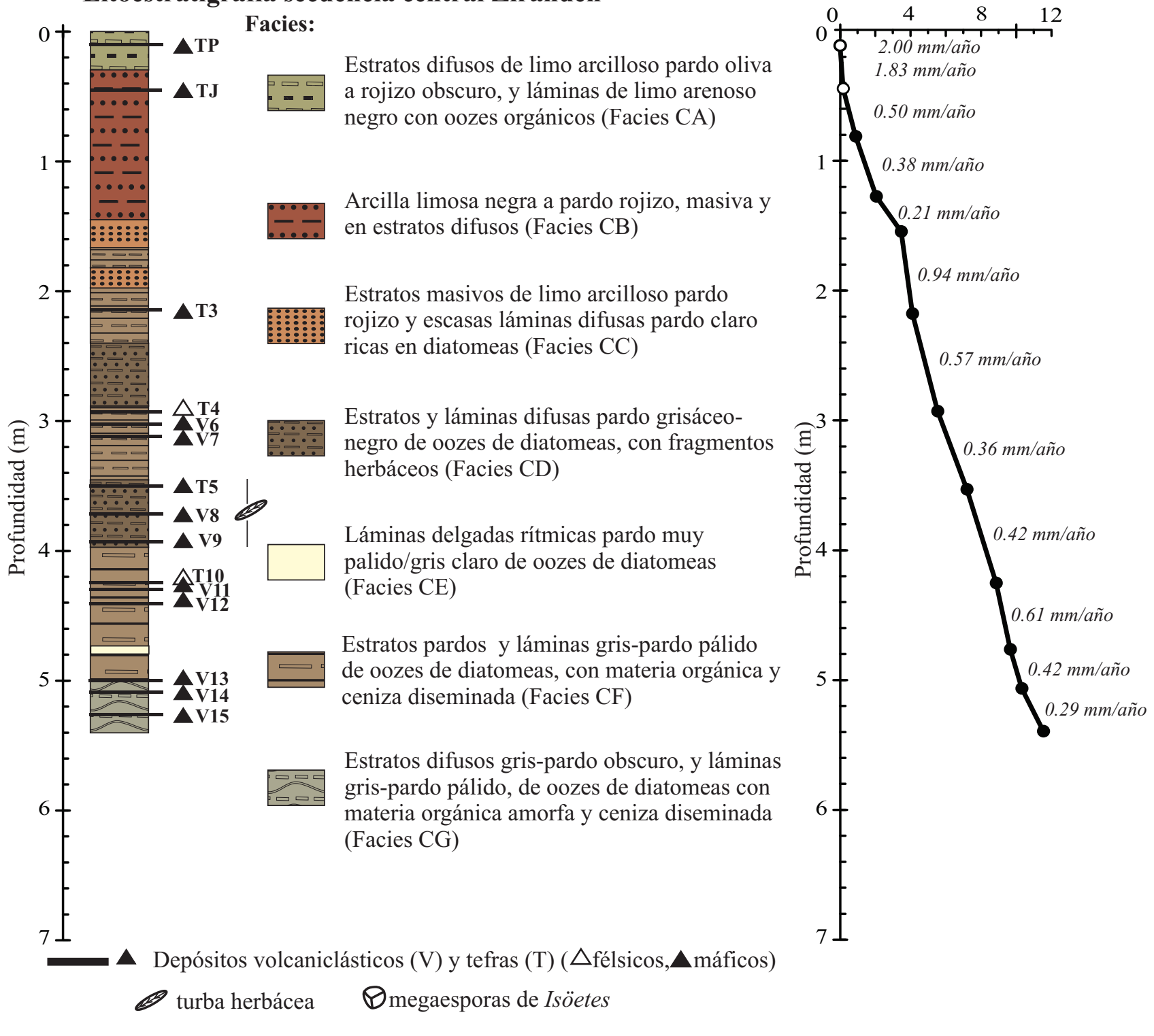

Figura 3. Litoestratigrafía y modelo de edad de la secuencia central. La curva del modelo de edad fue construida con los valores medios del intervalo de probabilidad de $2 \sigma$ de las edades calibradas, e incluye las tasas de sedimentación calculadas entre cada intervalo fechado, considerando la edad de la cima del depósito como el año de la colecta (2003).

(núcleo de Agua Verde - AV/98) (Davies et al., 2004). En ellos, las edades de ${ }^{210} \mathrm{~Pb}$ debajo de $10 \mathrm{~cm} 14 \mathrm{~cm}$ son tentativas, debido a que los errores son grandes a causa de una muy baja actividad de ${ }^{210} \mathrm{~Pb}$.

De acuerdo a estos modelos, la edad de los sedimentos en la base de la secuencia norte es de ca. 17000 años cal AP, en tanto los de la secuencia central abarcan hasta $c a .11540$ años cal AP. En la secuencia norte evidencias estratigráficas sustentadas en la cronología de ${ }^{14} \mathrm{C}$ indican un hiato en la sedimentación de aproximadamente $1 \mathrm{~m}$ de sedimento, equivalente a ca. 5000 años (Ortega et al., sometido), por lo que las secuencias se traslapan en edades posteriores a ca. 7200 años cal AP.
Las tasas de sedimentación dependen, entre otros factores, del ambiente de depósito (planicie lacustre central, talud, plataforma, litoral) y los procesos sedimentarios involucrados. Así mismo, estas tasas son ligeramente menores si se excluye el espesor de los depósitos volcaniclásticos. Sin embargo, debido a que las acumulaciones reconocidas como verdaderas tefras tienen en conjunto menos de $5 \mathrm{~cm}$ de espesor, las tasas calculadas permanecen prácticamente invariables considerando estos volcaniclastos. Las tasas de sedimentación varían entre 0.15 y $3.00 \mathrm{~mm} / \mathrm{año}$. Las más altas se presentan en los sedimentos superficiales posteriores al depósito de la tefra del Paricutín, entre 2.00 y $3.00 \mathrm{~mm} /$ año. La tasa de sedimentación estimada de la 
Tabla 1. Edades de radiocarbono en sedimentos de las secuencias norte y central del lago Zirahuén.

\begin{tabular}{|c|c|c|c|c|c|}
\hline Clave Laboratorio & $\begin{array}{l}\text { Profundidad } \\
(\mathrm{m})\end{array}$ & Tipo de muestra & $\begin{array}{c}\text { Edad Radiocarbono } \\
\text { (años AP) }\end{array}$ & $\begin{array}{c}\text { Edad calibrada } 2 \sigma \\
\text { (años AP) a }\end{array}$ & $\begin{array}{c}\text { Tasa de sedimentación } \\
\text { (mm/año) b }\end{array}$ \\
\hline TP & $0.12 \mathrm{C}$ & Tefra & & $*$ & 2.00 \\
\hline TJ & $0.45 \mathrm{C}$ & Tefra & & $*$ & 1.83 \\
\hline Beta - 221711 & $0.80 \mathrm{C}$ & polen & $990 \pm 40$ & $795-964$ & 0.50 \\
\hline Beta - 221712 & $1.25 \mathrm{C}$ & polen & $2090 \pm 40$ & $1949-2152$ & 0.38 \\
\hline Beta - 223997 & $1.55 \mathrm{C}$ & polen & $3230 \pm 40$ & $3377-3557$ & 0.21 \\
\hline SUERC - 8106 & $2.15 \mathrm{C}$ & sedimento orgánico & $3732 \pm 26$ & $4060-4152$ & 0.94 \\
\hline SUERC -8103 & $2.97 \mathrm{C}$ & sedimento orgánico & $4725 \pm 27$ & $5506-5582$ & 0.57 \\
\hline SUERC -8102 & $3.56 \mathrm{C}$ & sedimento orgánico & $6235 \pm 38$ & $7148-7256$ & 0.36 \\
\hline SUERC - 8104 & $4.27 \mathrm{C}$ & sedimento orgánico & $8014 \pm 48$ & $8715-9019$ & 0.42 \\
\hline Beta - 223999 & $4.76 \mathrm{C}$ & polen & $8710 \pm 40$ & $9547-9792$ & 0.61 \\
\hline Beta -223998 & $5.03 \mathrm{C}$ & polen & $9130 \pm 40$ & $10223-10407$ & 0.42 \\
\hline Beta - 221711 & $5.39 \mathrm{C}$ & sedimento orgánico & $10020 \pm 100$ & $11243-11834$ & 0.29 \\
\hline $\mathrm{TP}$ & $0.18 \mathrm{~N}$ & Tefra & & $*$ & 3.00 \\
\hline $\mathrm{TJ}$ & $0.42 \mathrm{~N}$ & Tefra & & $*$ & 1.33 \\
\hline Beta - 193855 & $0.50 \mathrm{~N}$ & sedimento orgánico & $770 \pm 50$ & $653-789$ & 0.15 \\
\hline Beta - 227821 & $0.91 \mathrm{~N}$ & sedimento orgánico & $1390 \pm 40$ & $1262-1377$ & 0.69 \\
\hline Beta -227822 & $1.52 \mathrm{~N}$ & sedimento orgánico & $2550 \pm 40$ & $2489-2643$ & 0.49 \\
\hline Beta - 193856 & $2.32 \mathrm{~N}$ & sedimento orgánico & $2870 \pm 40$ & $2871-3081$ & 1.95 \\
\hline Beta - 195351 & $3.05 \mathrm{~N}$ & sedimento orgánico & $4910 \pm 40$ & $5589-5720$ & 0.27 \\
\hline Beta - 233927 & $3.29 \mathrm{~N}$ & sedimento orgánico & $5490 \pm 40$ & $6260-6352$ & 0.37 \\
\hline Beta - 233928 & $3.49 \mathrm{~N}$ & sedimento orgánico & $5950 \pm 40$ & $6676-6882$ & 0.42 \\
\hline Beta - 193857 & $3.73 \mathrm{~N}$ & sedimento orgánico & $10290 \pm 60$ & $11945-12248$ & Hiato \\
\hline Beta - 195352 & $5.13 \mathrm{~N}$ & sedimento orgánico & $12850 \pm 50$ & $14947-15445$ & 0.45 \\
\hline Beta -193858 & $6.51 \mathrm{~N}$ & sedimento orgánico & $13980 \pm 80$ & $16250-17050$ & 0.95 \\
\hline
\end{tabular}

cronología de ${ }^{210} \mathrm{~Pb}$, en el periodo de 1901 a 1998 , es de aproximadamente $1.4 \mathrm{~mm} / \mathrm{año}$, semejante a la estimada para los sedimentos depositados entre las tefras del Paricutín y el Jorullo, 1.33 a $1.83 \mathrm{~mm} /$ año. Para sedimentos anteriores a la tefra del Jorullo, el promedio de la tasa de acumulación para las secuencias norte y central es de 0.92 y $0.71 \mathrm{~mm} /$ año respectivamente (Figuras 2 y 3 ).

\subsection{Correlación}

La correlación entre las secuencias norte y central está basada en la correspondencia de las curvas de susceptibilidad magnética y los depósitos volcaniclásticos claramente reconocidos como tefras: del Paricutín (TP), del Jorullo (TJ) y las tefras T3, T4 y T5 (Figuras 2 y 3). Las columnas estratigráficas y los registros de susceptibilidad magnética de cada secuencia han sido redibujados en su propia escala temporal, de acuerdo al modelo de edad establecido para cada una de ellas (Figura 4). La correlación únicamente es posible hacerla en sedimentos más jóvenes que $c a .7200$ años cal AP. De acuerdo a los modelos de edad, las edades para las tefras T5, T4 y T3 es de 7160 a 6900, 5500 a 5330 y 4140 a 4000 años cal AP respectivamente, en tanto la fecha considerada para la tefra Jorullo (TJ) es el año $1762 \mathrm{dC}$ y el año 1943 dC para la Paricutín (TP) (Tabla 1).
El registro de susceptibilidad magnética en la secuencia norte presenta los valores máximos obtenidos (hasta 7.8 $\mu^{3} / \mathrm{kg}$ ) y fluctuaciones de mayor amplitud que el registro central (máximos de $6.2 \mu \mathrm{m}^{3} / \mathrm{kg}$ ). Esto es debido a que los mayores contribuyentes a la susceptibilidad magnética en los sedimentos son los componentes clásticos, ricos en minerales ferrimagnéticos y paramagnéticos detríticos derivados de las rocas volcánicas circundantes y sus productos de alteración. Por otra parte, la susceptibilidad magnética es dependiente del tamaño de grano y aumenta con el incremento de tamaño de las partículas magnéticas (con excepción de las partículas superparamagnéticas). La franja litoral y la zona de rampa interna en el lago están sujetas a una mayor acumulación de minerales magnéticos gruesos, en tanto que la fracción más fina y menos densa de estos componentes sí alcanza la rampa externa y la planicie central del mismo. Las principales fluctuaciones en los registros de susceptibilidad magnética han sido designadas como los intervalos de máximos M1, M2 y M4, y el intervalo de mínimos M3 (Figura 4).

En los sedimentos de edad anterior a 4000 años cal AP, las fluctuaciones de susceptibilidad magnética son mínimas y no permiten establecer una correlación a partir de ella. En ellos únicamente es posible correlacionar las secuencias a partir de la presencia de tres tefras (T5, T4 y T3). De 


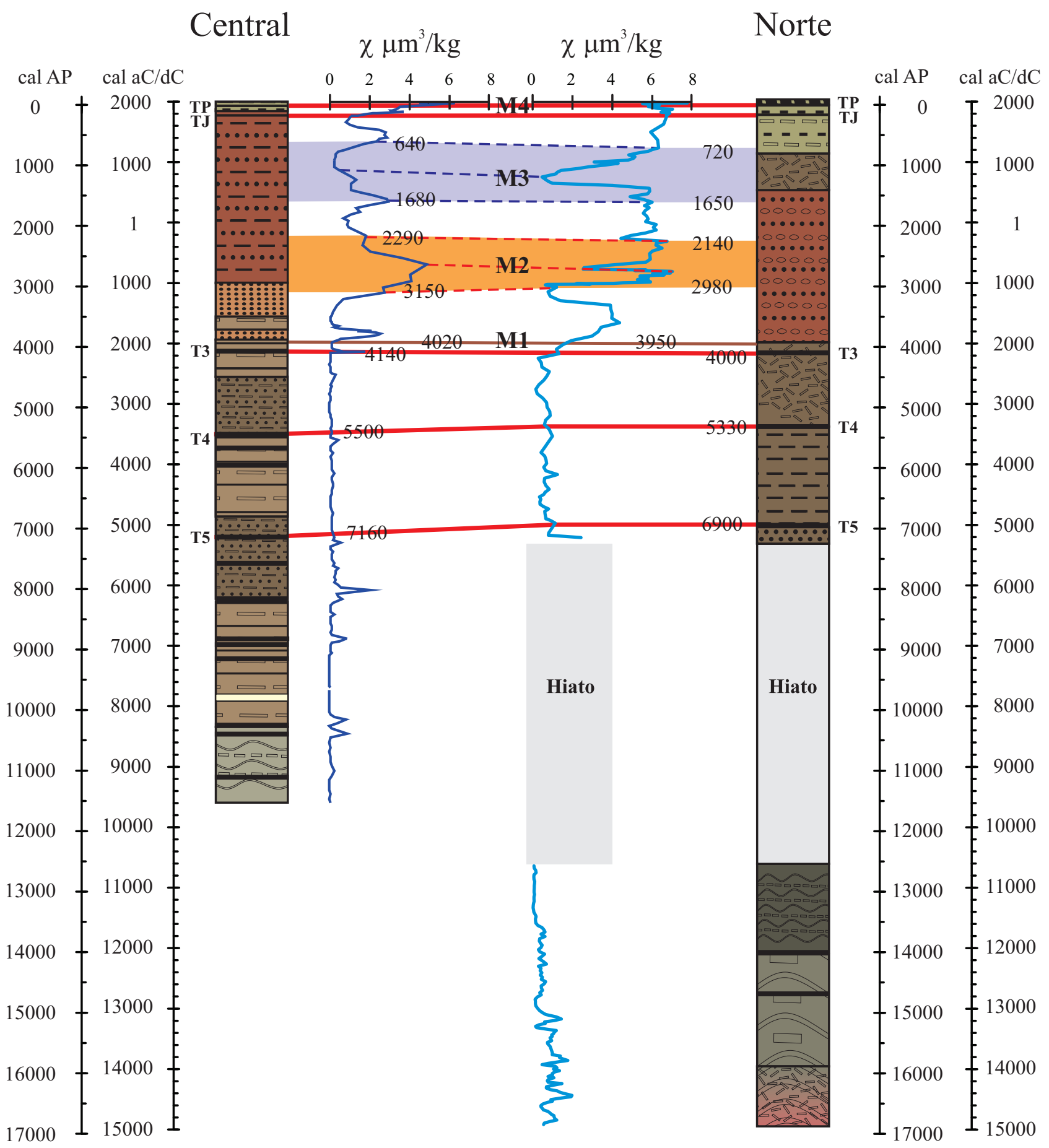

Figura 4. Correlación estratigráfica entre las secuencias norte y central del lago de Zirahuén, redibujadas en escala temporal de acuerdo al modelo de edad elaborado para cada una de ellas. La simbología se detalla en las figuras 2 y 3.

acuerdo a las edades calculadas para estos depósitos en cada secuencia, la diferencia máxima de edades entre ellas es de 260 años y se presenta en la tefra T5.

Poco después del depósito de la tefra T3, alrededor de 4000 años cal AP, inicia el aumento de susceptibilidad magnética. El primer incremento (M1) aparece de manera prácticamente sincrónica en ambas secuencias $(4020$ y
3950 años cal AP, Figura 4), se presenta como un máximo en $\chi$ de hasta $2.5 \mu \mathrm{m}^{3} / \mathrm{kg}$ de aproximadamente 400 años de duración en la secuencia central, en tanto que en la secuencia norte alcanza valores de $\chi>4 \mu \mathrm{m}^{3} / \mathrm{kg}$, con una duración de alrededor de 800 años. Los valores máximos ocurren con una diferencia de $c a .200$ años entre ambas secuencias, más temprano en la secuencia central que en la 
norte. Posteriormente disminuyen los valores de $\chi$, y después de $c a .3200$ años cal AP se establecen las condiciones de franca dominancia de sedimentación clástica (M2, Figura 4), registrados más temprano en la secuencia central con una diferencia también cercana a los 200 años entre ambas secuencias. La continuación de la sedimentación clástica reflejada en altos valores de $\chi$ de la secuencia norte entre ca. 2000 y 1650 años cal AP, no tiene una correspondencia en el registro central. Únicamente hay una correlación en la fluctuación mayor de $\chi$ hacia los valores mínimos de los registros (M3), correspondiente a las edades 1400 a 720 años cal AP en el norte y entre 1650 a 640 en el centro. Ambos registros de susceptibilidad magnética vuelven a coincidir plenamente en el incremento de la misma durante los últimos 50 años (M4). En el inicio de los incrementos de $\chi$ en M1 y M2, existe una diferencia sistemática de edades más jóvenes en el registro norte de 200 años o menos.

La falta de correlación uno a uno de los rasgos comparados puede tener varias causas. Entre otras, pueden ser las heterogeneidades de la acumulación de sedimentos en las diferentes regiones del lago (mayor acumulación de fracción más gruesa en la orilla que en el centro), el efecto derivado del origen distinto del carbono en las fracciones de material orgánico fechado (polen vs. sedimento orgánico total), las diferencias de edad entre la materia orgánica terrígena y el tiempo de acumulación del sedimento al cual se incorpora, las incertidumbres analíticas intrínsecas de cada fechamiento y las probables diferencias entre las tasas de acumulación reales, en comparación con las calculadas a partir de los modelos de edad. A pesar de estas incertidumbres, es posible establecer una buena correlación entre ambas secuencias si se consideran, además de los rasgos puntuales como la ocurrencia de tefras, tendencias más generales de máximos y mínimos de la susceptibilidad magnética.

\subsection{Facies y asociación de facies (Litoestratigrafía)}

Se definieron originalmente diecisiete facies, diez pertenecientes a la secuencia norte (Ortega et al., 2010) y siete a la parte central (Israde et al., en preparación), que corresponden a asociaciones de facies lacustres y aluviales (Fig. 5), cuyas características se detallan en la Tabla 2. La mayor parte de las facies sedimentarias reconocidas en el lago de Zirahuén consisten de oozes diatomáceos diferenciados por el color y el tipo de estratificación (masiva o laminada). La estructura laminada es más común en el sondeo central (facies CD, CE, CF y CG) y se encuentra desarrollada en menor proporción en el sondeo norte (facies NE y NG).

Las facies clásticas, las cuales siguen en abundancia a las diatomíticas, dominan en la parte superior de ambos sondeos, en parte diluyen el contenido biogénico y son en su mayoría masivas, posiblemente debido al aumento en la energía de sedimentación, la cual proporciona mayor cantidad de material terrígeno. En el norte, este fenómeno resulta en un aumento del tamaño de grano.

Las facies volcaniclásticas presentan acumulaciones $<$ $1 \%$ del espesor total de las secuencias, son más abundantes en la parte inferior de los sondeos (en estratos anteriores a los ca. 4100 años cal AP) y se presentan en capas o diseminados. La mayor parte de los depósitos volcaniclásticos está constituida por ceniza negra fina de fragmentos líticos máficos y cantidades variables de olivino y vidrio, cuyos espesores varían de 2 a $30 \mathrm{~mm}$ y se les designa de manera conjunta con la letra V. Algunos de estos depósitos son interpretados como tefras (designados con la letra T), es decir depósitos piroclásticos o de caída, de acuerdo a su composición, a las características morfológicas de los granos, a su continuidad lateral, así como la ausencia de estructuras derivadas de corrientes. Dentro de éstos únicamente se reconocieron tres cenizas félsicas de color pardo muy pálido a gris claro, compuestas por fragmentos de cuarzo, feldespato y vidrio, con espesores similares a las de composición máfica. Excepto en las tefras históricas de los volcanes Jorullo y Paricutín, son escasos los análisis geoquímicos y fechamientos publicados de lavas pleistocénicas y holocénicas en la región (Newton et al., 2005).

\subsubsection{Asociación de facies 4: $N J+N I+N H+N G$}

Esta asociación se encontró únicamente en la parte inferior del sondeo norte, entre el intervalo de 6.61 a 3.72 $\mathrm{m}$ de profundidad, al que corresponden una edad de $c a$. 16825 a 12100 años cal AP y una tasa de sedimentación promedio de $0.70 \mathrm{~mm} /$ año (Figura 5). Está compuesta principalmente de limo masivo rico en diatomeas. En la base, la facies NJ consiste de limo pardo obscuro rojizo masivo, rico en diatomeas, con un espesor de $0.60 \mathrm{~m}$, cambia transicionalmente hacia arriba a la facies NI, compuesta de limo pardo grisáceo masivo, rico en diatomeas, con 0.23 $\mathrm{m}$ de espesor. El contacto superior es difuso y horizontal. La facies $\mathrm{NH}$, limo gris obscuro masivo rico en diatomeas de 5.78 a $4.47 \mathrm{~m}$, tiene un cambio difuso y concordante a la facies NG, que consiste en un conjunto de $0.75 \mathrm{~m}$ de espesor (de 4.47 a $3.72 \mathrm{~m}$ de profundidad), de estratos rítmicos de ooze de diatomeas compuestos de capas gris obscuro masivas (2-14 $\mathrm{cm}$ espesor) y láminas a estratos irregulares pardo amarillo (2-40 mm espesor) con contactos difusos. En las facies NH y NG abundan fragmentos herbáceos $(3 \mathrm{~mm})$ y mega esporas de Isöetes $(<0.5 \mathrm{~mm})$, ligeramente más abundantes en la facies NG. En 4.92 y $4.49 \mathrm{~m}$ de profundidad se presentan dos cenizas negras irregulares, compuestas dominantemente de vidrio (V17 y V16, respectivamente), de 2 a $4 \mathrm{~cm}$ de espesor (Figura 2).

\subsubsection{Asociación de facies 3: $C G+C F+C E$}

Se definió únicamente en la base del sondeo central, entre $5.40-3.98 \mathrm{~m}$ de profundidad, cuya edad corresponde a ca. 11540 - 8180 años cal AP, y una tasa de sedimentación promedio de $0.44 \mathrm{~mm} / \mathrm{año}$. Está compuesta de oozes de diatomeas finamente laminados ( $<1 \mathrm{~cm}$ espesor) y estratos 
Tabla 2. Facies en sedimentos del lago Zirahuén.

\begin{tabular}{|c|c|}
\hline Facies & Características sedimentológicas \\
\hline \multicolumn{2}{|c|}{ Diatomáceas } \\
\hline ND & $\begin{array}{l}\text { Estratos gris oliva obscuro ( } 5 \text { Y } 3 / 2) \text { a negros ( } 5 \text { Y } 2.5 / 1) \text {, masivos, centimétricos a decimétricos, de ooze de diatomeas rico en } \\
\text { materia orgánica amorfa. }\end{array}$ \\
\hline $\mathrm{NE}$ & $\begin{array}{l}\text { Secuencia rítmica de ooze de diatomeas, compuesta de estratos gris muy obscuro ( } 5 \mathrm{Y} 3 / 1) \text {, de } 1 \text { a } 10 \mathrm{~cm} \text { de espesor, en alternancia } \\
\text { con láminas pardo obscuro ( } 7.5 \mathrm{YR} 3 / 3) \text { a negro }(7.5 \mathrm{YR} 2.5 / 1) \text { de } 2 \text { a } 5 \mathrm{~mm} \text { de espesor, suborizontales a horizontales. Los contactos } \\
\text { son rectos a irregulares. }\end{array}$ \\
\hline NG & $\begin{array}{l}\text { Ooze diatomítico gris muy obscuro ( } 5 \mathrm{Y} 3 / 1 \text { ), masivo a moteado (negro, } 5 \mathrm{Y} 2.5 / 1) \text {, en estratos de } 2 \text { a } 14 \mathrm{~cm} \text { de espesor (dominantes), } \\
\text { que alternan de manera rítmica con láminas y estratos irregulares pardo amarillento (10YR } 5 / 4) \text { de ooze de diatomeas } \\
\text { (subordinados), de } 2 \mathrm{~mm} \text { a } 4 \mathrm{~cm} \text { de espesor. Subhorizontales a inclinados }\left(>30^{\circ}\right) \text {, con contactos difusos. Abundantes restos } \\
\text { herbáceos de hasta } 3 \mathrm{~mm} \text { longitud, y megaesporas de Isöetes }(<0.5 \mathrm{~mm} \text { diámetro). }\end{array}$ \\
\hline NH & $\begin{array}{l}\text { Limo gris muy obscuro (10YR 3/1) con cambios difusos a limo pardo obscuro amarillento (10YR 4/4) en escala centimétrica, } \\
\text { masivo, rico en diatomeas. Presenta escasos estratos delgados }(1 \mathrm{a} 2 \mathrm{~cm}) \text {, irregulares de arena negra }(10 \mathrm{YR} 2 / 1) \text { diseminada. } \\
\text { Abundantes restos herbáceos de hasta } 3 \mathrm{~mm} \text { longitud, y megaesporas de Isöetes }(<0.5 \mathrm{~mm} \text { diámetro). }\end{array}$ \\
\hline NI & $\begin{array}{l}\text { Limo pardo muy obscuro grisáceo (10YR 3/2), masivo, con escasos estratos centimétricos ( } 2 \text { a } 5 \mathrm{~cm} \text { ) de limo negro ( } 5 \text { YR } 2.5 / 1) \text {, } \\
\text { rico en diatomeas. }\end{array}$ \\
\hline NJ & $\begin{array}{l}\text { Limo pardo obscuro rojizo (5YR 3/4), masivo, rico en diatomeas. En la base de la secuencia norte cambia gradualmente a la facies } \\
\text { NI a lo largo de } 22 \mathrm{~cm} \text {. }\end{array}$ \\
\hline $\mathrm{CD}$ & $\begin{array}{l}\text { Ooze de diatomeas en estratos difusos y láminas pardo grisáceo }(10 \mathrm{YR} 5 / 2) \text { a negro }(10 \mathrm{YR} 2 / 1) \text {, de } 0.5 \text { a } 10 \mathrm{~cm} \text { de espesor, con } \\
\text { fragmentos macroscópicos herbáceos, y escasas láminas de ooze de diatomeas pardo muy pálido (10YR } 7 / 3) \text {. Las capas son } \\
\text { horizontales, con contactos tenues y rectos. }\end{array}$ \\
\hline $\mathrm{CE}$ & $\begin{array}{l}\text { Laminas finas }(0.5 \text { a } 5 \mathrm{~mm}) \text { rítmicas pardo muy pálido (10YR } 7 / 3) / \text { gris claro }(10 \mathrm{YR} 7 / 1) \text { de oozes de diatomeas. Los contactos son } \\
\text { nítidos, ondulados. En la secuencia central (donde es reconocida) presenta } 5 \mathrm{~cm} \text { de espesor. }\end{array}$ \\
\hline $\mathrm{CF}$ & $\begin{array}{l}\text { Estratos pardo obscuro (10YR } 3 / 3) \text { a pardo }(10 \text { YR } 4 / 3) \text { de } 1 \text { a } 3 \mathrm{~cm} \text { de espesor y láminas gris claro }(10 \mathrm{YR} 7 / 1) \text { a pardo muy pálido } \\
\text { (10YR } 7 / 3) \text {, todos ellos compuestos de ooze de diatomeas, con materia orgánica amorfa y ceniza fina máfica diseminada. } \\
\text { Subhorizontales, con contactos difusos a nítidos, rectos a ondulados. }\end{array}$ \\
\hline CG & $\begin{array}{l}\text { Estratos y láminas gris muy obscuro ( } 7.5 \mathrm{YR} 3 / 1) \text { a pardo obscuro ( } 7.5 \mathrm{YR} 3 / 3) \text { de } 1 \text { a } 3 \mathrm{~cm} \text { de espesor (dominantes), y láminas } \\
\text { subordinadas gris claro ( } 7.5 \mathrm{YR} 7 / 1) \text { a pardo muy pálido (10YR } 7 / 3) \text { de } 2 \text { a } 10 \mathrm{~mm} \text { de espesor, todas ellas compuestas de oozes de } \\
\text { diatomeas y materia orgánica amorfa, con ceniza fina máfica diseminada. Subhorizontales, con contactos difusos a nítidos, rectos a } \\
\text { ondulados. }\end{array}$ \\
\hline
\end{tabular}

\section{Clásticas}

NA

NB

NC

NF

CA

CB

$\mathrm{CC}$

\section{Volcaniclásticas}

TP

TJ

$\mathrm{T} 3$

T4

T5

$\mathrm{V}(6$ a 17)
Limo arcilloso pardo grisáceo muy obscuro (10YR 3/2), diatomáceo, masivo.

Limo arcilloso pardo muy obscuro grisáceo (10YR 3/2) a pardo (10YR 4/3), diatomáceo, en láminas difusas subhorizontales de 0.3 a $1 \mathrm{~mm}$ de espesor.

Limo arcilloso pardo obscuro rojizo (5YR 3/2), en estratos $>2 \mathrm{~cm}$ a masivo, con abundantes fitolitos y bajo contenido de diatomeas, alternan con arena fina a media negra (5YR 2.5/1) en estratos de 4 a $7 \mathrm{~cm}$ de espesor, con clastos subangulares de vidrio volcánico, plagioclasa, ocasionales anfíboles y minerales opacos, con restos de materia orgánica herbácea y carbón. Los contactos son difusos, irregulares o inclinados. En los núcleos colectados rápidamente se oxida y adquiere un tono más rojo en las superficies de corte.

Limo arenoso pardo obscuro (10YR 3/3) a gris muy obscuro (5Y 3/1), masivo, rico en materia orgánica amorfa y fragmentos de diatomeas. Los clastos de arena son fragmentos de plagioclasa zonada y piroxeno.

Limo arcilloso pardo oliva obscuro (2.5Y 3/3) a pardo rojizo obscuro (5YR 3/3), en estratos difusos de escala centimétrica (2-5 cm) subhorizontales, y láminas $(0.5-1 \mathrm{~cm})$ de limo arenoso negro (5YR 2.5/1) con oozes orgánicos.

Arcilla limosa negra (7.5YR 2.5/1), gris muy obscuro (7.5YR 3/1) a pardo obscuro rojizo (5YR 3/4), de estructura masiva y en estratos difusos de escala centimétrica, con fragmentos de cuarzo y feldespatos de tamaño limo, fragmentos de materia orgánica hebácea y leñosa diseminada, y diatomeas.

Limo arcilloso pardo obscuro (7.5YR 3/2) a pardo obscuro rojizo (2.5YR 3/4), masivo y en estratos difusos, con contactos muy irregulares. Escasas láminas difusas pardo claro (7.5YR 6/3) y negras (7.5YR 2.5/1) ricas en diatomeas, subhorizontales.

Tefra de ceniza negra (10YR 2/1) de $2 \mathrm{~cm}$ de espesor, compuesta principalmente de fragmentos angulares de vidrio, plagioclasa y minerales máficos. Este depósito corresponde a la tefra del volcán Paricutín.

Tefra de ceniza negra (10YR 2/1) diseminada en un intervalo de $2 \mathrm{~cm}$ de espesor, compuestos de vidrio, plagioclasa y minerales máficos, que corresponden a la tefra del volcán Jorullo.

Tefra de ceniza muy fina, negra (10YR 2/1), de $3 \mathrm{~cm}$ de espesor, compuesta de fragmentos angulosos de vidrio máfico, olivino y liticos de roca volcánica, con fragmentos de diatomeas procedentes de la columna de agua.

Tefra de ceniza muy fina, pardo muy pálido (10YR 8/2), con fragmentos angulares de vidrio con inclusiones de microcristales y fenocristales rotos de feldespato, plagioclasa zonada y escasos máficos como accesorios. Presenta escasos bioclastos (diatomeas y fragmentos herbáceos). En el sondeo norte tiene un espesor de $5 \mathrm{~mm}$, en tanto que en la secuencia central aparece como dos intervalos discretos de $c a .2 \mathrm{~mm}$ de espesor cada uno, separados por sedimentos orgánicos de $1.5 \mathrm{~mm}$ de espesor.

Tefra de ceniza negra (10YR 2/1) de $2 \mathrm{~cm}$ de espesor, compuesta de plagioclasa, vidrio y minerales máficos. Depósitos volcaniclásticos gris obscuro (10YR 4/1) a negro (10YR 2/1), masivos, irregulares. Sus espesores oscilan de $5 \mathrm{~mm}$ a 3 $\mathrm{cm}$, presentan fragmentos angulosos de líticos de roca volcánica máfica y cantidades variables de olivino y vidrio..Su matriz se encuentra representada por cantidades variables de diatomeas de diferentes tamaños y materia organica fina diseminada que procede de la columna de agua, además se presentan algunos fragmentos subredondeados de cuarzo y feldespato. 


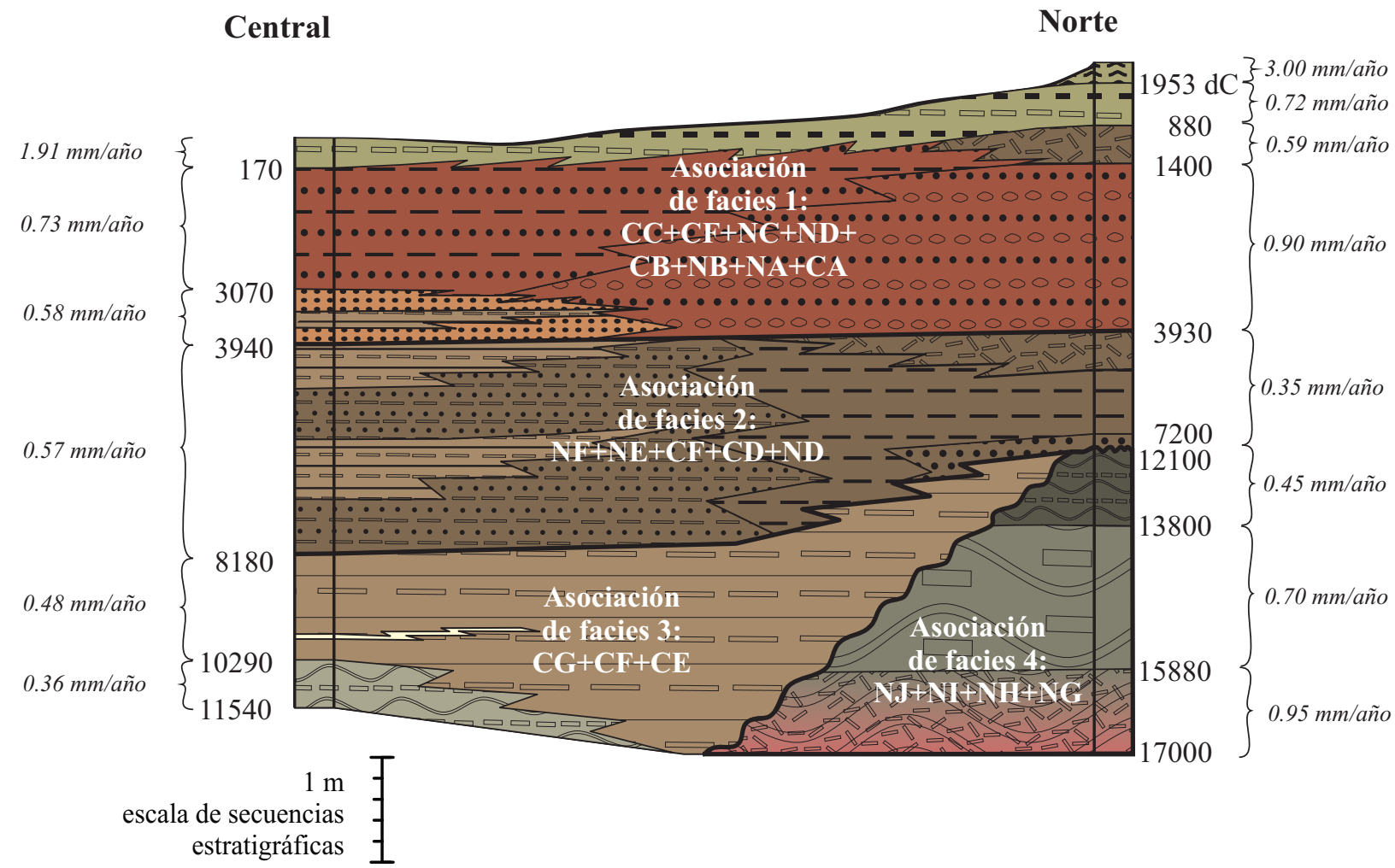

Figura 5. Facies y asociación de facies de las secuencias norte y central del lago de Zirahuén. A ambos lados se presentan las tasas de sedimentación promedio y sus límites en edades calibradas para las distintas asociaciones de facies.

( $\geq 1 \mathrm{~cm}$ espesor), generalmente bien definidas (facies $\mathrm{CG}$, $\mathrm{CF}$ y $\mathrm{CE}$ ), con algunas facies volcaniclásticas intercaladas (T10 y V15 a V11). La facies CG, que ocurre entre la base y $4.99 \mathrm{~m}$ de profundidad, $c a .11540$ y 10290 años cal AP, consiste de estratos difusos y láminas gris muy obscuro a pardo obscuro de 1 a $3 \mathrm{~cm}$ de espesor, con láminas gris claro a pardo muy pálido, todas ellas compuestas de oozes de diatomeas, materia orgánica amorfa y ceniza fina máfica diseminada (Figura 6a). La facies CF se presenta en el intervalo de 4.99 a $3.98 \mathrm{~m}$ de profundidad, $c a .10290 \mathrm{y}$ 8180 años cal AP, está compuesta de estratos de color pardo obscuro a pardo, de 1 a $3 \mathrm{~cm}$ de espesor y láminas gris claro a pardo muy pálido, compuestas de oozes de diatomeas, materia orgánica amorfa y ceniza fina diseminada de composición máfica (Figura 6b). Presenta una sección distintiva de $5 \mathrm{~cm}$ de espesor (facies CE, 4.84 a $4.79 \mathrm{~m}$ de profundidad, $c a$. 9880 a 9780 años cal AP) con finas láminas $(0.5$ a $5 \mathrm{~mm})$ rítmicas pardo muy pálido/gris claro de oozes de diatomeas. El contacto entre las facies CG y CF es concordante y difuso, definido por la desaparición de las capas gris muy obscuro de la facies CF. Los estratos más obscuros tienen mayor contenido de materia orgánica amorfa que las laminaciones. No se observa el contacto entre la asociación de facies 3 y la subyacente asociación 4.

\subsubsection{Asociación de facies 2: $N F+N E+C F+C D+N D$}

En la secuencia central se presenta en el intervalo de 3.98 a $1.98 \mathrm{~m}$ de profundidad, con edad de $c a .8180$ a 3940 años cal AP, en tanto que en la secuencia norte está entre 3.72 $2.57 \mathrm{~m}$ de profundidad, con una edad correspondiente a $c a$. 7200 - 3930 años cal AP. Las tasas de sedimentación varían de 0.57 a $0.35 \mathrm{~mm} / \mathrm{año}$, respectivamente. Está compuesta de ooze de diatomeas rico en materia orgánica, en estratos y láminas generalmente difusos (facies $\mathrm{NE}, \mathrm{CF}, \mathrm{CD}$ ), intervalos masivos (facies ND), así como por los depósitos de la facies clástica NF y las volcaniclásticas T5, T4, T3 y V9 a V6. En la base de esta asociación de facies en la secuencia norte, la facies NF descansa discordantemente sobre el depósito de la facies NG de la asociación de facies 4. Las características de este contacto, abrupto e irregular, así como la discontinuidad en el modelo de edad establecido para la secuencia norte, indican que parte del registro sedimentario está ausente en esta secuencia y se infiere un hiato entre $c a .12100$ y 7200 años cal AP, en el que la extrapolación de las tasas de sedimentación indican la pérdida de alrededor de un metro de sedimentos.

La sedimentación se restablece con el depósito de la facies NF, que consisten de limo arenoso pardo obscuro, masivo, rico en materia orgánica, en el intervalo de 3.72 $-3.61 \mathrm{~cm}$, cuya edad corresponde a $c a .7200-7020$ años cal AP, con una tasa de sedimentación promedio de $0.42 \mathrm{~mm} / \mathrm{año}$. Esta facies no tiene una equivalente en la secuencia central, por lo que se infiere un acuñamiento de sus sedimentos. Sobre la anterior descansan de manera 
a)

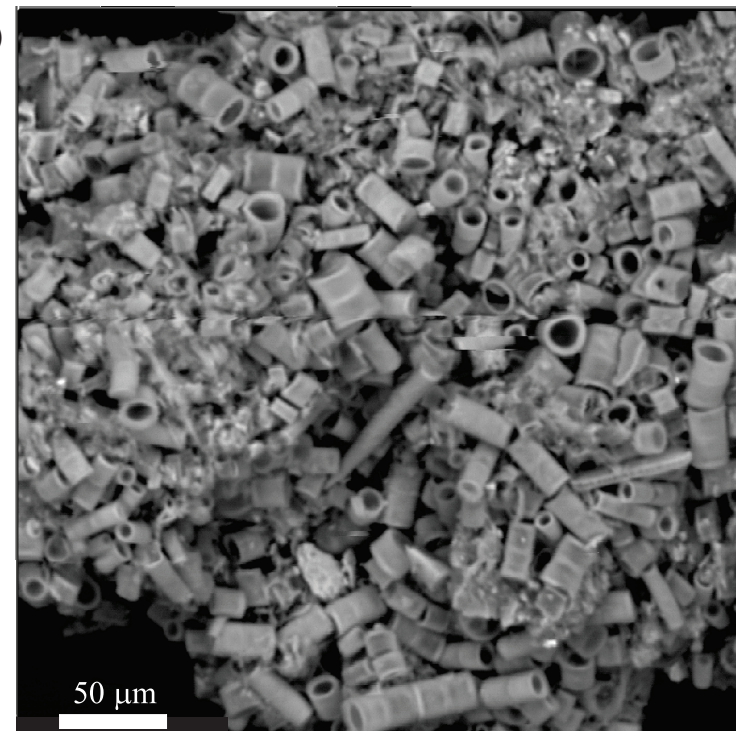

b)

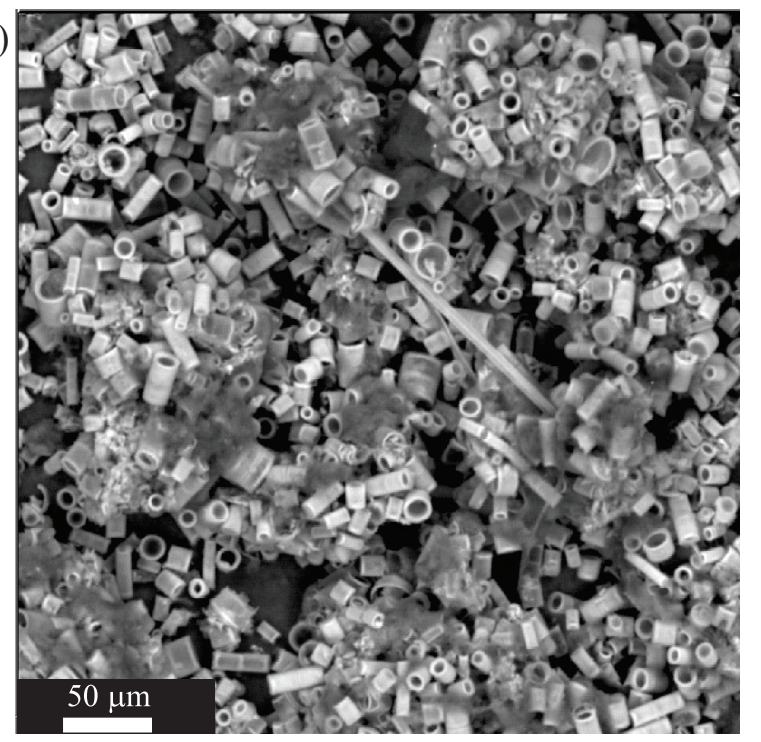

c)

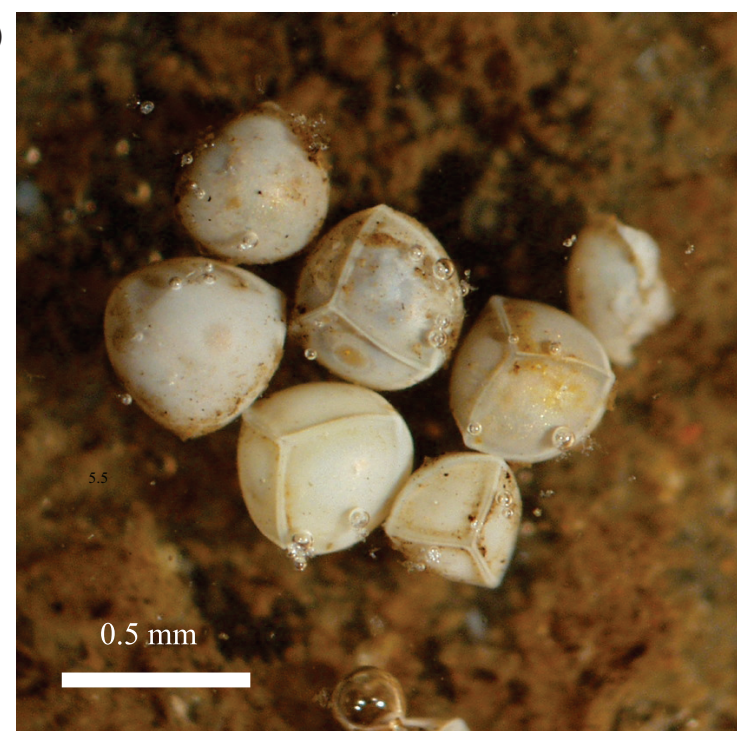

Figura 6. Fotomicrografías de las facies sedimentarias CG (a) y CF (b) observadas en los núcleos profundos de los sedimentos del lago de Zirahuén. Megaesporas de Isöetes de las facies NG y NH (c).

concordante los sedimentos de la facies NE, que consisten de una secuencia rítmica de ooze diatomáceo en la que alternan estratos $(1-7 \mathrm{~cm})$ gris obscuro con láminas $(2-5$ $\mathrm{mm}$ ) pardo obscuro. Esta facies presenta un espesor de 0.56 $\mathrm{m}$, con edad entre $c a .7020$ y 5560 años cal AP y una tasa de sedimentación promedio de $0.35 \mathrm{~mm} /$ año. Esta facies cambia lateralmente a las facies $\mathrm{CD}$ y $\mathrm{CF}$ del sondeo central (Figura 5).

La facies CD se presenta en dos intervalos, entre 3.98 $3.44 \mathrm{~m}, c a .8180-6890$ años cal AP y entre 2.91 y $2.40 \mathrm{~m}$ de profundidad, $c a .5480$ - 4640 años cal AP. Las tasas de sedimentación en esta facies varían entre 0.39 y $0.57 \mathrm{~mm} /$ año. Está compuesta de estratos y láminas difusos pardo grisáceo a negro de oozes de diatomeas, con fragmentos macroscópicos herbáceos. En esta asociación, la facies CF se encuentra en dos intervalos, entre $3.44-2.91 \mathrm{~m}, c a$. $6890-5480$ años cal AP y $2.40-1.98 \mathrm{~m}, c a .4640-3940$ años cal AP, con tasas de acumulación entre 0.46 y 0.75 $\mathrm{mm} /$ año. Los contactos entre las facies de esta asociación son concordantes y difusos.

La facies ND (secuencia norte), está compuesta de ooze gris obscuro masivo, en el intervalo entre $3.05-2.57$ $\mathrm{m}$ de profundidad, cuya edad corresponde al periodo de 5560 - 3930 años cal AP y tiene una tasa de sedimentación promedio de $0.27 \mathrm{~mm} /$ año. El contacto con los depósitos subyacentes de la facies NE es concordante y horizontal. Esta facies no tiene una equivalente en la secuencia central, por lo que se infiere un acuñamiento de sus sedimentos. 
En esta asociación de facies están presentes las tefras $\mathrm{T} 5$, compuesta de plagioclasa, vidrio y minerales máficos; la tefra T4, una ceniza blanca compuesta de vidrio, plagioclasa y escasos minerales máficos y la tefra T3; así como los depósitos volcaniclásticos V9-V6.

\subsubsection{Asociación de facies 1: \\ $\mathrm{CC}+\mathrm{CF}+\mathrm{NC}+\mathrm{ND}+\mathrm{CB}+\mathrm{NB}+\mathrm{NA}+\mathrm{CA}$}

En la secuencia central se encuentra de $1.98 \mathrm{~m}$ de profundidad a la superficie, intervalo al que corresponde una edad de 3940 años cal AP - $2003 \mathrm{dC}$, con una tasa de sedimentación promedio de $0.98 \mathrm{~mm} /$ año. En la secuencia norte está entre $2.57-0 \mathrm{~m}$ de profundidad, en el periodo de 3930 años cal AP - 2003 dC y tiene una tasa de sedimentación promedio de $1.12 \mathrm{~mm} /$ año. Está compuesta principalmente de material clástico (arena, limo y arcilla) con algunos intervalos ricos en diatomeas y materia orgánica amorfa que en los núcleos colectados rápidamente se oxida y adquiere un tono rojo/anaranjado en las superficies de corte. Los clastos más gruesos son vidrio volcánico, plagioclasa, ocasionales anfíboles y minerales opacos, así como cuarzo cubierto de una capa de arcilla roja y feldespatos alterados. La fracción arcillosa identificada por DRX es halloysita. La dominancia de los componentes clásticos en esta asociación se refleja en los altos valores de susceptibilidad magnética $(\chi)$. El contacto con la unidad inferior es concordante, transicional y difuso, definido por la aparición de los estratos de limo arcilloso.

En la secuencia central, la base de esa asociación está constituida por una alternancia de facies $\mathrm{CC}-\mathrm{CF}-\mathrm{CC}$, en el intervalo de $1.98-1.45 \mathrm{~m}$ de profundidad ( $c a .3940-3070$ años cal AP). La tasa de sedimentación promedio es de $0.58 \mathrm{~mm} / \mathrm{año}$, en la que alternan estratos masivos de limo arcilloso pardo obscuro a pardo obscuro rojizo y escasas láminas difusas pardo claro ricas en diatomeas (facies CC). La facies laminada CF se encuentra en el intervalo 1.82 $1.65 \mathrm{~m}, 3760$ - 3590 años cal AP, con tasa de acumulación de $0.94 \mathrm{~mm} /$ año. En contacto concordante sobre las facies arriba descritas, se encuentran los depósitos de la facies CB, compuesta de arcilla limosa negra, gris muy obscuro a pardo obscuro rojizo, con estructura masiva y estratos difusos, con fragmentos de cuarzo y feldespatos de tamaño limo. Abarca el intervalo de $1.45-0.30 \mathrm{~m}$ de profundidad, corresponde al periodo de 3070 - 170 años cal AP y tiene una tasa de sedimentación promedio de $0.73 \mathrm{~mm} /$ año.

En la secuencia norte, la base de esta asociación presenta los sedimentos de la facies NC, compuesta por estratos de limo arcilloso pardo obscuro rojizo $(2-20 \mathrm{~cm})$. Son masivos, con abundantes fitolitos y bajo contenido de diatomeas; alternan con estratos de arena negra (4- 7 $\mathrm{cm})$. Este depósito tiene un espesor de $1.63 \mathrm{~m}$, abarca el periodo de $c a .3930$ a 1400 años cal AP, con una tasa de sedimentación promedio de $0.90 \mathrm{~mm} /$ año. El contacto con la asociación de facies 2 inferior es concordante y difuso. Sobre la facies NC se presenta un depósito de $34 \mathrm{~cm}$ de espesor que corresponde a la facies ND, cuyas características fueron descritas en la sección anterior. La edad de este depósito es de $c a .1400-880$ años cal AP, abarca el intervalo de $0.94-0.60 \mathrm{~m}$ de profundidad, con una tasa de sedimentación promedio de $0.59 \mathrm{~mm} / \mathrm{año}$. El conjunto de facies $\mathrm{CC}-\mathrm{CF}-\mathrm{CC}-\mathrm{CB}$ de la secuencia central cambia lateralmente al conjunto de facies NC-ND de la secuencia norte (Figura 5).

La parte superior de esa asociación de facies está constituida por las facies CA-NB. La facies CA está constituida por estratos difusos de escala centimétrica ( 2 a $5 \mathrm{~cm}$ ) de limo arcilloso pardo oliva obscuro a pardo rojizo obscuro y láminas $(0.5 \mathrm{a} 1 \mathrm{~cm})$ de limo arenoso negro con oozes orgánicos. Abarca los $0.30 \mathrm{~m}$ superficiales de la secuencia central, correspondientes a los últimos $c a$. 170 años, que representan una tasa de sedimentación de $1.91 \mathrm{~mm} / \mathrm{año}$. Los sedimentos rápidamente se oxidan en superficies de corte. El contacto inferior es gradual, definido por la aparición de las láminas negras en la facies CA y la marcada disminución en la intensidad de oxidación en superficies expuestas por cortes.

La facies NB, compuesta de láminas $(0.3$ a $1 \mathrm{~mm}$ de espesor) de limo arcilloso y diatomáceo pardo grisáceo, que abarca el intervalo de $0.60-0.20 \mathrm{~m}$ de profundidad, durante el periodo de $880-33$ años cal AP, con una tasa de sedimentación promedio de $0.72 \mathrm{~mm} /$ año. Descansa de manera concordante sobre el depósito subyacente de la facies ND.

La facies NA está constituida de limo arcilloso pardo muy obscuro grisáceo, diatomáceo y masivo, presente en los $20 \mathrm{~cm}$ superiores de la secuencia norte, abarca los últimos $c a .86$ años y presenta una tasa de sedimentación promedio de $3.00 \mathrm{~mm} / \mathrm{año}$.

Entre $0.42-0.43 \mathrm{~m}$, se encuentran fragmentos volcaniclásticos diseminados compuestos de vidrio, plagioclasa y minerales máficos, que corresponden a la tefra Jorullo (TJ). A $0.18-0.20 \mathrm{~m}$ se encuentra otra tefra de ceniza negra compuesta principalmente de fragmentos angulares de vidrio, plagioclasas y minerales máficos, que corresponde a la tefra Paricutín (TP).

\section{Discusión}

\subsection{La morfología del lago}

De acuerdo al mapa batimétrico elaborado por BernalBrooks y MacCrimmon (2000a) el depocentro de lago Zirahuén se localiza en la parte oeste, en el extremo opuesto de la desembocadura del río La Palma, en lo que probablemente fue uno de los puntos más bajos de su cauce anterior al cierre de la cuenca por los flujos de lava de $\mathrm{La}$ Magueyera. En general, el borde este del lago presenta una rampa lacustre más amplia (entre 1 y $1.3 \mathrm{~km}$ ), con una pendiente más suave de $c a \cdot 1.5^{\circ}$, en parte debido al relieve original anterior a la formación del lago, así como a los depósitos aluviales del río La Palma y de las escorrentías 
que cortan el cerro Zirahuén. Hacia el norte del lago, en el sector donde fue colectada la secuencia norte, la rampa tiene menor amplitud que aquella en el sector este (entre 250 y 700 $\mathrm{m}$ de longitud), con un ángulo entre 3 y $7^{\circ}$, debido en parte al relieve heredado y a que las escorrentías provenientes del arroyo El Chorrito, del cerro Tumbio y la parte NW del cerro Zirahuén al norte del lago, son de menor importancia que las localizadas al este del mismo. Hacia el oeste del lago, la pendiente cambia abruptamente frente a los cerros La Magueyera y Cumburinos (Figura 1), los cuales son las acumulaciones volcánicas más jóvenes en la cuenca y no han desarrollado aún una disección fluvial importante, formando una zona de pequeña plataforma y talud en el lago.

Cabría esperar que la planicie central y el depocentro hacia el oeste del lago albergaran las secuencias lacustres de mayor espesor. Sin embargo, las tasas de sedimentación en el sondeo norte son en general más altas que las estimadas en el sondeo central, lo que indica la influencia de la sedimentación clástica en el borde del lago.

\subsection{El registro lacustre de la actividad volcánica}

Las facies volcaniclásticas presentan acumulaciones $<$ $1 \%$ del espesor total de las secuencias, son más abundantes en la parte inferior de los sondeos, donde se presentan en capas o diseminadas. Durante la perforación en la parte central, la penetración de la tubería terminó abruptamente debido probablemente a la presencia de algún estrato de gran competencia en la base del sondeo, por lo que se pensó que se había llegado a un depósito volcaniclástico resistente, muy compacto, de espesor mayor a varios centímetros. Sin embargo, no se colectó ningún material semejante en la base del sondeo central. Por otra parte, en el sondeo norte, en cuya secuencia está ausente el depósito equivalente a la base del central, tampoco se registró ningún depósito volcaniclástico mayor a $5 \mathrm{~cm}$ de espesor. La mayor parte de los volcaniclastos son de composición máfica, y solo tres tefras son de composición félsica. Por los delgados espesores de los depósitos volcaniclásticos, se considera que se trata de emisiones distales con relativamente bajo impacto en el ambiente del lago y su entorno. Se reconocieron las tefras históricas de los volcanes Jorullo y Paricutín a partir de sus características petrográficas y sus relaciones estratigráficas. Aunque en el presente trabajo no se han realizado análisis geoquímicos en las tefras que permitan intentar correlacionarlas con las caracterizadas en la región del CVMG, por la edad y sus características macroscópicas, la tefra T3 puede corresponder a la tefra CA/T404 del lago de Pátzcuaro (Newton et al., 2005).

\subsection{Las tasas de sedimentación}

Los sedimentos del lago Zirahuén registran importantes cambios verticales y laterales. Los componentes sedimentarios varían principalmente dentro de tres extremos que son la materia orgánica, las frústulas de diatomeas y los sedimentos terrígenos; en consecuencia, las variaciones en la proporción de estos tres componentes principales definen las facies sedimentarias. Las tasas de sedimentación promedio en las asociaciones de facies descritas varían entre $0.44 \mathrm{y}$ $0.98 \mathrm{~mm} / \mathrm{año}$ en la secuencia central y entre 0.35 y 1.12 $\mathrm{mm} / \mathrm{año}$ en la secuencia norte.

El mayor aporte de sedimentos fluviales al lago es a través del río La Palma, cuya desembocadura se encuentra al $\mathrm{SE}$, y que drena una área de $180 \mathrm{~km}^{2}$. En un núcleo colectado frente a la desembocadura del río (ZR/98), se encontraron tasas de sedimentación de $10 \mathrm{~mm} /$ año para los últimos 55 años (Davies et al., 2004). Este aporte de terrígenos, en la actualidad controlado por los campos cultivados y los canales de irrigación, pudo tener alguna influencia en el sitio donde fue colectada la secuencia central. Sin embargo, esta influencia debió haber sido menor aún en el sitio de colecta de la secuencia norte. Para el sitio norte, el arrastre superficial de sedimentos proviene de una área de drenaje $c a$. 10 veces menor que la cuenca del río La Palma. Otros controles en la sedimentación terrígena -como el tectonismo, la acumulación o denudación por derrumbes asociados a fallamiento sinsedimentario o la perturbación de los sedimentos por sismicidad-, no han sido considerados en este esquema, ya que no se cuenta con información de zonas más extensas en la cuenca.

En la asociación de facies 4 la tasa de sedimentación promedio es de $0.70 \mathrm{~mm} /$ año. Estos sedimentos compuestos de limo y diatomeas tienen bajos valores de $\chi$, lo que indica un contenido relativamente bajo de minerales ferrimagnéticos (titanomagnetitas principalmente, de origen clástico, de acuerdo a las temperaturas de Curie y análisis por microsonda electrónica), que son los principales contribuyentes a la susceptibilidad magnética. Sin embargo, el conjunto de facies NJ y NI presentan una de las tasas de sedimentación más altas encontradas $(0.95 \mathrm{~mm} / \mathrm{año})$. El tono rojizo de estos sedimentos sugiere la presencia de óxidos y oxihidróxidos de hierro (p.e. hematita, lepidocrocita, goethita), minerales comúnmente clásticos formados por la oxidación de minerales de Fe pero que contribuyen débilmente a la susceptibilidad magnética. La presencia de estos minerales explicaría las tasas de sedimentación relativamente altas, debidas a una mayor contribución clástica, y los bajos valores de susceptibilidad magnética en las facies NJ-NI.

Las asociaciones de facies 3 y 2, dominadas por ooze de diatomeas y materia orgánica amorfa, presentan tasas de sedimentación similares, entre 0.35 y $0.57 \mathrm{~mm} / \mathrm{año}$. En la asociación de facies 1 las tasas de sedimentación varían entre 0.98 y 1.12 mm/año. Las mayores tasas de sedimentación se encuentran en la cima de ambas secuencias, por arriba del depósito de la tefra del Paricutín, donde alcanzan 3 $\mathrm{mm} /$ año. De acuerdo a los intervalos fechados, una tasa de sedimentación relativamente alta se localiza en una parte de los sedimentos de la facies NC entre las edades de 2980 y 2715 años cal AP (1.95 mm/año, figura 2) aunque la tasa calculada para todo el depósito de esta facies es 
de $0.90 \mathrm{~mm} / \mathrm{año}$, semejante a las calculadas en las facies ND y NB por arriba de ella. De acuerdo a la estratigrafía descrita y a los valores de $\chi$, en esta asociación de facies se presenta la mayor cantidad de sedimentos terrígenos. Sin embargo, en el conjunto de las facies de esta asociación en la secuencia norte, las tasas calculadas son semejantes a las de la asociación de facies 4 (Figura 5).

\subsection{Las láminas}

La laminación se presenta mejor desarrollada en los sedimentos de la asociación de facies 3, en la secuencia central, facies CF y CD. En la secuencia norte, si bien la laminación y la estratificación en general están menos definidas que en la secuencia central, son también reconocibles intervalos laminados en los sedimentos de las facies NG y NE, por debajo de la tefra T4. En todas estas facies, las láminas están compuestas por oozes de diatomeas. En los sedimentos de la asociación de facies 1 las láminas son escasas y difusas. Los intervalos laminados reflejan periodos de mayor estabilidad y condiciones de menor energía durante la sedimentación en el lago. En lagos tropicales, el desarrollo de pares de láminas anuales está asociado a cambios en las estaciones secas y húmedas (Glenn y Kelts, 1991), sin embargo no se ha determinado cuál es el origen de la laminación en Zirahuén, aunque se considera que puede representar la alternancia de condiciones estables interrumpidas por periodos de fuerte mezcla de agua que aumentaron la disponibilidad de nutrientes, disparando el florecimiento de las diatomeas que se depositaron para formar las láminas.

\subsection{Historia del depósito}

Los últimos ca. 17000 años de historia del lago de Zirahuén pueden esbozarse a partir de las evidencias presentadas en este trabajo. En ninguno de los sondeos colectados se alcanzó el sustrato del lago y la ausencia de fechamientos absolutos en las acumulaciones volcánicas que se asume cerraron el drenaje del río La Palma, impide estimar con mayor precisión la edad mínima de formación del lago. La existencia de frústulas de diatomeas, la mayor parte de ellas en buen estado de preservación, así como la ausencia de rasgos asociados a la formación de paleosuelos, indican que los sedimentos colectados tanto en el centro como en el norte se acumularon en ambientes subacuáticos. Las principales etapas de desarrollo del lago de Zirahuén se ilustran de manera esquemática en la figura 7.

\subsubsection{Etapa 1: Pleistoceno tardio, ca. 17000-14000 años cal AP}

Domina la sedimentación clástica de grano fino (limo), aunque es abundante el contenido de diatomeas. El color rojo de los sedimentos implica la acumulación de una fracción clástica relativamente rica en óxidos u oxihidróxidos de $\mathrm{Fe}$ formada por el intemperismo o la alteración de minerales de $\mathrm{Fe}$, y su posterior conservación en el lago en un ambiente óxico. Las tasas de sedimentación relativamente altas, la estructura masiva de los sedimentos, con abundantes fragmentos herbáceos y esporas de Isöetes en NH sugieren un ambiente ribereño, de bajos niveles lacustres, posiblemente de condiciones climáticas relativamente secas. La transición en la coloración de los sedimentos, de rojiza en la base a gris obscuro en la cima, indica un cambio gradual a condiciones reductoras en el ambiente de depósito, y una disminución en el ingreso de minerales derivados del intemperismo.

\subsubsection{Etapa 2: Transición Pleistoceno tardío-Holoceno, ca. 14000 a 8180 años cal AP}

En la secuencia norte, entre 14000 y 12100 años cal AP, la composición de los sedimentos cambia al volverse dominantes las diatomeas, y empieza a definirse la estratificación y la laminación (facies NG). En esta secuencia son más abundantes aún los fragmentos herbáceos y las esporas de Isöetes. En nuestros sondeos no existe el registro sedimentario entre $c a .12100$ y 11540 años cal AP. En la secuencia central se presenta la laminación más fina y mejor desarrollada entre $c a .11540$ y 8180 años cal AP, lo que sugiere que las condiciones bajo las cuales empieza a desarrollarse la laminación en la secuencia norte, continúan hasta $c a .8180$ años cal AP. Posiblemente la fina laminación se desarrolló durante un periodo con una estacionalidad más marcada, durante épocas de una estratificación más intensa o duradera en la columna de agua con bajo aporte de sedimentos por erosión superficial, o por un aumento en el nivel lacustre. Así mismo, el incremento en Isöetes indica la expansión del litoral. Se considera que estos sedimentos representan las condiciones más estables de los registros.

\subsubsection{Etapa 3: Holoceno temprano y medio, ca. 8180 a 3900 años cal AP}

En la secuencia norte no hay registro sedimentario entre 12100 y 7200 años cal AP. Una probable explicación del origen del hiato es el descenso del nivel lacustre y la exposición de los sedimentos a la deflación. Por otra parte, es posible también que se haya originado por una transgresión erosiva. En la secuencia central, el depósito de la facies CD es la única evidencia de cambios en la sedimentación, sin embargo, hay una diferencia de alrededor de 1000 años entre el inicio de la acumulación de la facies CD y la reanudación de la sedimentación en la secuencia norte (facies NF). En la secuencia norte no hay rasgos que sugieran una exposición aeróbica de los sedimentos (p.e. oxidación, paleosuelos, superficies endurecidas, grietas de desecación, etc.), que apoyen la hipótesis de la disminución del nivel lacustre. Por otra parte, en la secuencia central, localizada a aproximadamente $2 \mathrm{~km}$ de la secuencia norte, no hay evidencias del depósito de los sedimentos removidos por una erosión transgresiva (p.e. incremento en las tasas de sedimentación, aumento de tamaños de grano, etc.), excepto por la presencia de fragmentos herbáceos. Las 

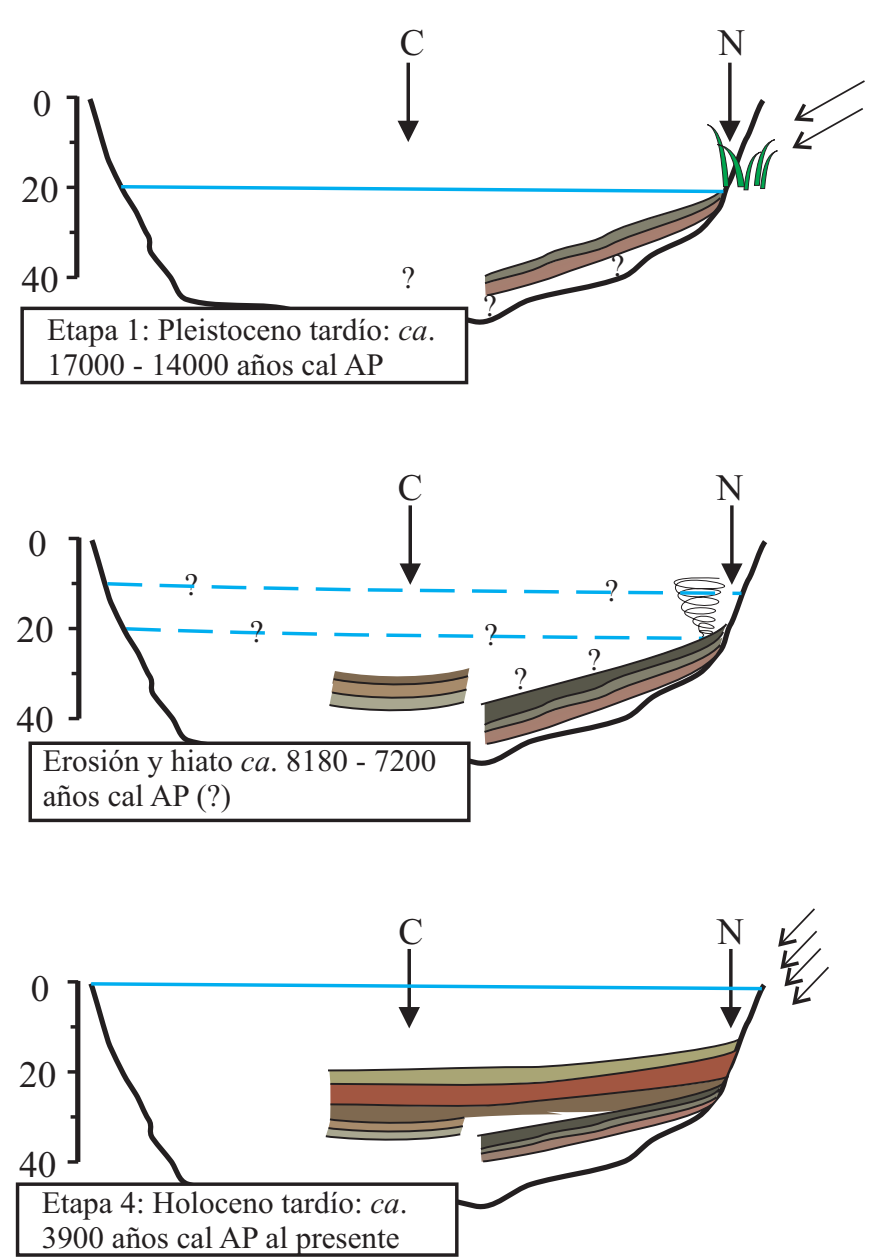
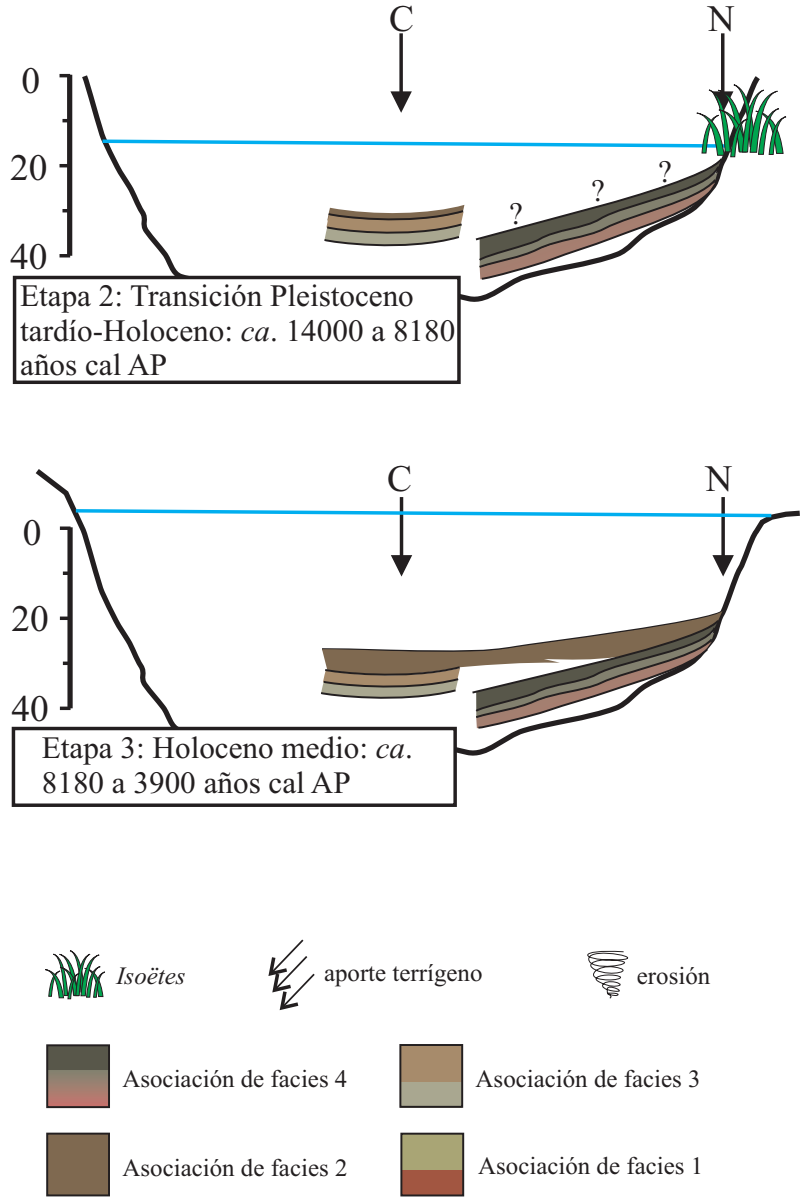

Figura 7. Evolución del lago Zirahuén en los últimos $c a$. 17000 años. En la etapa 1 y 2 el lago se expande y se profundiza. Un evento erosivo alrededor de 7300 años cal AP produce un hiato en la secuencia norte de alrededor de 5000 años. En la etapa 3 continua el ascenso del nivel lacustre, y en la etapa 4 se registra un intenso aporte de terrígenos.

evidencias aquí encontradas no son suficientes para apoyar la ocurrencia de uno u otro de los procesos que ocasionaron el hiato.

Después de $c a .8180$ años cal AP, la laminación en la secuencia central pierde definición. A medida en que aumenta el contenido de materia orgánica, el sedimento pierde su carácter laminado y el depósito se vuelve masivo. La alternancia de facies CF y CD indican variaciones en los procesos que dieron origen a la laminación. La sedimentación en la secuencia norte se reanuda con la acumulación de material clástico arenoso, y posteriormente al depósito de la tefra $\mathrm{T} 5$ se restaura la formación de estratos delgados y láminas. En estos sedimentos desaparecen los Isöetes. Tanto por la presencia de materia orgánica como por la abundancia de diatomeas, se infiere que es alta la productividad en el lago. Estas evidencias sugieren un ascenso del nivel lacustre que provocó la inundación del ambiente litoral donde crecían los Isöetes, y el desarrollo de laminaciones en los sedimentos de la secuencia norte, posiblemente indicando condiciones ambientales relativamente más húmedas.

\subsubsection{Etapa 4: Holoceno tardío, ca. 3900 años cal AP al presente}

Después de los 4000 años cal AP se registra el mayor cambio en la sedimentación lacustre. Este periodo está dominado por los componentes terrígenos. La alternancia de estratos de limo rojizo con horizontes de arena en la secuencia norte, y de arcilla limosa en el centro, sugieren variaciones en la energía de las corrientes superficiales que erosionaron, transportaron y finalmente depositaron los terrígenos. El sedimento fue derivado tanto de la erosión de materiales volcaniclásticos frescos como de materiales alterados y suelos. En este ambiente erosivo, en algunos intervalos discretos de la facies $\mathrm{NC}$ de la secuencia norte (entre 2916 y 1360 años cal AP), las diatomeas tienen una pobre preservación y son los fitolitos la fracción bioclástica mejor conservada. Estas características indican que hubo pulsos de intensa erosión, probablemente debido a fuertes precipitaciones, esporádicas o periódicas, en presencia de 
un terreno con poca cubierta arbórea en el que los suelos resultaron expuestos a la erosión. Estas evidencias sugieren la ocurrencia de importantes variaciones climáticas, en las cuales la precipitación pudo haber sido el factor que controló la erosión. Por otra parte, aunque en Zirahuén el registro arqueológico de ocupación humana es escaso, en Pátzcuaro se ha documentado una importante ocupación e impacto humano desde hace ca. 4000 años (O'Hara et al., 1993), aunque otros autores estiman que el mayor impacto ocurrió a raíz de la conquista, cuando los habitantes abandonaron la región (Fisher et al., 2003). En Zirahuén la presencia de granos de polen de maíz en estas secuencias sedimentarias (Lozano et al., 2010) indica la existencia de actividades agrícolas en la cuenca al menos desde ca. 3000 años cal AP, y por lo tanto el impacto humano debió ser también un factor importante en los cambios ambientales inferidos.

A partir de $c a$. 1650 años cal AP inicia una disminución en el aporte de terrígenos, identificado en los registros de susceptibilidad magnética como el mínimo M3 (Figura 4). La disminución en el aporte de terrígenos puede estar relacionada con una reducción en la precipitación. Este rasgo tiene una expresión más clara en los sedimentos del sondeo norte, tanto en la composición de los sedimentos (facies ND) como en los valores de $\chi$ entre $c a .1400$ y 880 años cal AP, equivalentes al periodo 550 - $1070 \mathrm{dC}$. Este intervalo corresponde al final del periodo arqueológico Clásico, tiempo durante el cual varias de las mayores culturas mesoamericanas alcanzaron su máximo desarrollo y llegaron a un rápido colapso. Varios autores sugieren que en esta declinación cultural, el establecimiento de recurrentes sequías fueron un factor determinante (e. g., Hodell et al., 1995). El incremento de los procesos erosivos después del año $1100 \mathrm{dC}$ coincide con el máximo desarrollo de los Purépechas o Tarascos (Pulido et al., 1996). Posteriormente se restablece el aporte de terrígenos, principalmente en la zona norte, y a partir de la caída de la tefra del Paricutín, en los últimos 60 años hay una notable acumulación de terrígenos en ambas secuencias.

\section{Conclusiones}

Las dos secuencias sedimentarias recuperadas, fechadas por ${ }^{14} \mathrm{C}$ y analizadas en sus componentes sedimentarios, indican una edad mínima de 17000 años cal AP del lago de Zirahuén. Las secuencias en conjunto constituyen uno de los registros más continuos en el centro de México que abarcan el fin del último glacial, cercano al UMG, y el Holoceno en su totalidad.

En estas secuencias el análisis de las facies sedimentarias permitió elaborar un modelo de la evolución ambiental. Las facies sedimentarias que se infiere se encuentran relacionadas genéticamente a partir de su correlación estratigráfica y temporal, han sido agrupadas en cuatro asociaciones. La correlación de facies es posible hacerla únicamente en sedimentos más jóvenes que $c a$. 7200 años cal AP. La asociación de facies 4 en la parte inferior de la secuencia norte, no tiene un equivalente en la secuencia central. Así mismo, la asociación de facies 3 del núcleo central tampoco tiene un equivalente en la secuencia norte debido a la existencia de un hiato en el mismo.

En sedimentos anteriores a 4000 años cal AP, las facies consisten principalmente de oozes diatomáceos diferenciados por el color y el tipo de estratificación (masiva o laminada). En sedimentos más recientes dominan las facies clásticas mayormente masivas, las cuales presentan los mayores valores de susceptibilidad magnética. Las facies volcaniclásticas representan $<1 \%$ del espesor total, y por sus delgados espesores se trata de emisiones distales con relativamente bajo impacto en el lago y su entorno. Entre ellas se reconocieron las tefras históricas de los volcanes Jorullo y Paricutín.

Las variaciones en las características de los componentes sedimentarios analizados reflejan la evolución del lago Zirahuén en cuatro etapas principales. 1) Bajos niveles lacustres y dominancia de sedimentación clástica de grano fino entre 17000 y 14000 años cal AP. 2) Expansión del litoral y aumento del nivel lacustre entre 14000 a 8180 años cal AP, bajo condiciones relativamente estables. Un evento erosivo probablemente ocurrido entre 8180 y 7200 años cal AP produce un hiato en la secuencia norte de alrededor de 5000 años, equivalente a un espesor de $1 \mathrm{~m}$ de sedimentos. 3) Continúa el ascenso del nivel lacustre en condiciones de alta bioproductividad. 4) Se registra un intenso aporte de terrígenos. Es difícil separar las señales climáticas y de impacto humano en el incremento en la erosión registrado después de 4000 años cal AP. Sin embargo, es posible que existieran importantes variaciones climáticas, en las cuales la precipitación pudo haber sido el factor que controló la erosión de un terreno con una pobre cubierta vegetal, ya fuera por el impacto humano o por la ocurrencia de prolongados periodos secos. Se reconoce un periodo de baja erosión entre $c a$. 1400 y 880 años cal AP, que sugiere la extensión de las condiciones secas inferidas en otros sitios de Mesoamérica al final del periodo arqueológico Clásico.

\section{Agradecimientos}

Este trabajo fue financiado por los proyectos UNAMDAGPA IN107902, IN114906, IN113408, IN212606 y el CONACYT 28528-T, así como Aberystwyth University Research Fund y NERC Radiocarbon Steering Commitee, El Limnological Research Center (University of Minnesota) proporcionó la tecnología y experiencia para colectar los núcleos de la parte profunda y las facilidades para su descripción inicial. Nuestro profundo agradecimiento a D. Schnurrenberger, A. Noren y M. Shapley por su ayuda en campo y durante la documentación inicial y descripción litoestratigráfica del núcleo central (proyecto Mexican Lakes, MOLE). J.A. González, A. Rodríguez, L. Oseguera y M. Caballero realizaron la perforación de la secuencia norte. 
M.S. Lozano, S. Metcalfe, M. Caballero e I. Israde asistieron durante la perforación del núcleo MOLE. C. Linares asistió en la toma de las imágenes MEB. G. Vázquez recibió la beca No. 163229 del CONACyT para llevar a cabo sus estudios de doctorado. B. Aston recibió una beca de posgrado de Aberystwyth University Postgraduate Research Studentship. Los autores agradecemos los comentarios de dos revisores anónimos que ayudaron a mejorar el manuscrito.

\section{Referencias}

Bernal-Brooks, F.W., MacCrimmon, H.R., 2000a, Lake Zirahuen (Mexico): An assessment of the morphometry change based on evidence of water level fluctuations and sediment inputs, in Munawar, M., Lawrence, S.G., Munawar, I.F., Malley, D.F. (eds.), Aquatic ecosystems of Mexico. Status and Scope: Leiden, Ecovision World Monogram Series, Backhuys Publishers, 61-76.

Bernal-Brooks, F.W., MacCrimmon, H.R., 2000b, Lake Zirahuen, México: a pristine natural reservoir visually insensitive to expected cultural eutrophication, in Munawar, M., Lawrence, S.G., Munawar, I.F., Malley, D.F. (eds.), Aquatic ecosystems of Mexico: Status and Scope: Leiden, Ecovision World Monogram Series, Backhuys Publishers, 77-88.

Bradbury, J.P., 1989, Late Quaternary lacustrine paleoenvironments in the Cuenca de Mexico: Quaternary Science Reviews, 8, 75-100.

Bradbury, J.P., 2000, Limnologic history of Lago de Patzcuaro, Michoacan, Mexico, for the past 48000 years: impacts of climate and man: Palaeogeography, Palaeoclimatology, Palaeoecology, 163, 69-95.

Caballero, M., Lozano, S., Ortega, B., Urrutia, J., Macías, J.L., 1999, Environmental characteristics of Lake Tecocomulco, northern basin of Mexico, for the last 50000 years: Journal of Paleolimnology, $22,99-411$.

Caballero, M.M., Ortega, G.B., 1998, Lake levels since about 40000 years ago at lake Chalco, near Mexico City: Quaternary Research, $50,69-79$.

Clausing, A., Boy, J.A., 2000, Lamination and primary production in fossil lakes: relationship to palaeoclimate in the Carbonuferous-Permian transition, in Hart, M.B. (ed.), Climates: Past and Present: London, Geological Society, Special Publications, 181, 5-16.

Davies, S.J., Metcalfe, S.E., MacKenzie, A.B., Newton, A., Endfield, G.H., Farmer, J.G., 2004, Environmental changes in the Zirahuen basin, Michoacán, Mexico, during the last 1000 years: Journal of Paleolimnology, 31, 77-98

Fisher, C., Pollard, H., Israde, I., Garduño, V., Banerjee, S., 2003, A reexamination of human-induced environmental change within the Lake Pátzcuaro Basin, Michoacán, Mexico: Proceedings of the National Academy of Sciences of the USA, 100-8, 4957-4962.

García, E., 1990, Carta de Clima, IV.4.10. Climas: Atlas Nacional de México, Vol. II, Naturaleza: México, Instituto de Geografía, UNAM.

Garduño, V., Rodríguez M., Israde, I., 2004, Evidencias paleosísmicas en fallas activas y sedimentos deformados del lago de Pátzcuaro, Jarácuaro, Michoacán, México: Geotemas 6(3), 151-154.

Glenn, C.R., Kelts, K., 1991, Sedimentary rhythms in lake deposits, in Einsele, G. Ricken, W., Seilacher, A., (eds.), Cycles and events in stratigraphy: Berlin, Springer, 592-607.

Hasenaka, T., Carmichael, I.S.E., 1985, The cinder cones of MichoacanGuanajuato, central Mexico: their age, volume and distribution and magma discharge rate: Journal of Volcanology and Geothermal Research, 25, 105-124.

Hodell, D.A., Curtis, J.H., Brenner, M., 1995, Possible role of climate in the collapse of Classic Maya civilization: Nature, 375, 391-394.

Israde, I., Davies, S., Aston, B., Vazquez, G., en preparación, Holocene record of climatic and environmental change from the Zirahuen Basin, central Mexico: sediment stratigraphy, age model and diatom assemblages: The Holocene.
Israde, A.I., Garduño, M.V.H., Ortega, M.R., 2002, Paleoambiente lacustre del Cuaternario tardío en el centro del lago Cuitzeo: Hidrobiológica, $12,61-78$.

Lozano, G.S., Ortega, G.B., 1998, Late Quaternary environmental changes of the central part of the Basin of Mexico; correlation between Texcoco and Chalco sub-basins: Review of Palaeobotany and Palynology, 99, 77-93.

Lozano, G.S., Ortega, G.B., Caballero, M.M., Urrutia, F.J., 1993, Late Pleistocene and Holocene paleoenvironments of the Chalco Lake, Central Mexico: Quaternary Research, 40, 332-342.

Lozano-García, M.S., Sosa-Nájera, S., Sugiura, Y., Caballero, M., 2005, 23000 years of Vegetation History of the Upper Lerma, a tropical high altitude basin in central Mexico: Quaternary Research, 64, 70-82.

Lozano-García, M.S., Vázquez-Castro, G., Israde-Alcántara, I., 2010, Registro palinológico de la perturbación humana y natural de los últimos 3,200 años en el Lago de Zirahuén, centro-occidente de México, en Ortiz, C.F., Rendón, M.B. (eds.), El espejo de los dioses: estudios sobre ambiente y desarrollo en la cuenca del lago de Zirahuén: Morevallado, Morelia Michoacán, Edición de ININEE-INIRENA.

Metcalfe, S., 1995, Holocene environmental change in the Zacapu basin, Mexico: a diatom-based record: The Holocene, 5, 196-208.

Metcalfe, S.E., Davies, S.J., Braisby, J.D., Leng, M.J., Newton, A.J., Terrett, N.L., O'Hara, S.L., 2007, Long and short-term change in the Patzcuaro Basin, central México: Palaeogeography, Palaeoclimatology, Palaeoecology, 247, 272-295.

Metcalfe, S.E., Street-Perrot, F.A., Perrot, R.A., Harkness, D.D., 1991, Paleolimnology of the Upper Lerma basin, central Mexico: a record of climatic change and anthropogenic disturbance since $11600 \mathrm{yr}$ BP: Journal of Paleolimnology, 5, 197-218.

Mingram, J., Negendank, J.F.W., Brauer, A., Berger, D., Hendrich, A., Köhler, M., Usinger, H., 2007, Long cores from small lakesrecovering up to $100 \mathrm{~m}$-long lake sediments sequences with a high precision rod-operated piston corer (Usinger-corer): Journal of Paleolimnology, 37(4), 517-528.

Newton, A.J., Metcalfe, S.E., Davies, S.J., Cook, G., Baker, P., Telford, R.J., 2005, Late Quaternary volcanic records from lakes of Michoacan, central Mexico: Quaternary Science Reviews, 24, 91-104.

O'Hara, S., Street-Perrot F.A., Burt T.P., 1993, Accelerated soil erosion around a Mexican highland lake caused by prehispanic agriculture: Nature, 362, 48-51.

Ortega, B., Caballero, C., Lozano, S., Israde, I., Vilaclara, G., 2002, 52000 years of environmental history in Zacapu Basin, Michoacan, Mexico: The magnetic record: Earth and Planetary Science Letters, 202, 663-675.

Ortega, B., Vazquez, G., Caballero, M., Israde, Isabel., Lozano, S., Schaaf, P., Torres, E., 2010, Late Pleistocene - Holocene record of environmental changes in lake Zirahuen, central Mexico: Journal of Paleolimnology, 44(3), 745-760.

Pulido, M.S., Cabrera, T.J.J., Grave, T.L.A., 1996, Proyecto carretera Patzcuaro-Uruapan. Informe final: Mexico, Archivo técnico de la Dirección de Salvamento Arqueológico-INAH.

Reimer, P.J., Baillie, M.G.L., Bard, E., Bayliss, A., Beck, J.W., Bertrand, C.J.H., Blackwell, P.G., Buck, C.E., Burr, G.S., Cutler, K.B., Damon, P.E., Edwards, R.L., Fairbanks, R.G., Friedrich, M., Guilderson, T.P., Hogg, A.G., Hughen, K.A., Kromer, B., McCormac, F.G., Manning, S.W., Ramsey, C.B., Reimer, R.W., Remmele, S., Southon. J.R., Stuiver, M., Talamo, S., Taylor, F.W., Plicht, J., Weyhenmeyer, C.E., 2004, IntCa104 Terrestrial radiocarbon age calibration 26 - 0 ka BP: Radiocarbon, 46, 1029-1058.

Schnurrenberger, D., Russell, J., Kelts, K., 2003, Classification of lacustrine sediments base don sedimentary components: Journal of Paleolimnology, 29, 141-154.

Stuiver, M., Reimer, P., 1993, Extended ${ }^{14} \mathrm{C}$ data base and revised Calib 3.0 14C calibration program: Radiocarbon, 35, 215-230.

Stuiver, M., Reimer, P., Reimer, R.W., 2005, CALIB 5.0 program and documentation (on line), version Calib 5.0.2: United Kingdom, $<$ http://calib.qub.ac.uk/calib/calib.html $>$ 
Zolitschka, B., Brauer, A., Negendank, J.F.W., Stockhausen, H., Lang, A., 2000, Annually dated late Weichselian continental paleoclimate record from the Eifel, Germany: Geology, 28, 783-786.
Manuscrito recibido: Agosto 20, 2009.

Manuscrito corregido recibido: Enero 11, 2010.

Manuscrito aceptado: Febrero 8, 2010. 